\title{
Engineering Pseudomonas protegens Pf-5 for Nitrogen Fixation and its Application to Improve Plant Growth under Nitrogen-Deficient Conditions
}

\author{
Lorena Setten $^{1}$, Gabriela Soto ${ }^{1,2}$, Matteo Mozzicafreddo ${ }^{3}$, Ana Romina Fox ${ }^{2}$, Christian Lisi ${ }^{1}$, \\ Massimiliano Cuccioloni ${ }^{3}$, Mauro Angeletti ${ }^{3}$, Elba Pagano ${ }^{1}$, Antonio Díaz-Paleo ${ }^{1}$, Nicolás Daniel Ayub ${ }^{1,2 *}$
}

1 Instituto de Genética Ewald A. Favret (CICVyA-INTA), Castelar, Buenos Aires, Argentina, 2 Consejo Nacional de Investigaciones Científicas y Técnicas (CONICET), Cuidad Autónoma de Buenos Aires, Argentina, $\mathbf{3}$ School of Biosciences and Biotechnology, University of Camerino, Camerino (MC), Italy

\begin{abstract}
Nitrogen is the second most critical factor for crop production after water. In this study, the beneficial rhizobacterium Pseudomonas protegens Pf-5 was genetically modified to fix nitrogen using the genes encoding the nitrogenase of Pseudomonas stutzeri A1501 via the X940 cosmid. Pf-5 X940 was able to grow in L medium without nitrogen, displayed high nitrogenase activity and released significant quantities of ammonium to the medium. Pf-5 X940 also showed constitutive expression and enzymatic activity of nitrogenase in ammonium medium or in nitrogen-free medium, suggesting a constitutive nitrogen fixation. Similar to Pseudomonas protegens Pf-5, Pseudomonas putida, Pseudomonas veronii and Pseudomonas taetrolens but not Pseudomonas balearica and Pseudomonas stutzeri transformed with cosmid X940 showed constitutive nitrogenase activity and high ammonium production, suggesting that this phenotype depends on the genome context and that this technology to obtain nitrogen-fixing bacteria is not restricted to Pf-5. Interestingly, inoculation of Arabidopsis, alfalfa, tall fescue and maize with Pf-5 X940 increased the ammonium concentration in soil and plant productivity under nitrogen-deficient conditions. In conclusion, these results open the way to the production of effective recombinant inoculants for nitrogen fixation on a wide range of crops.
\end{abstract}

Citation: Setten L, Soto G, Mozzicafreddo M, Fox AR, Lisi C, et al. (2013) Engineering Pseudomonas protegens Pf-5 for Nitrogen Fixation and its Application to Improve Plant Growth under Nitrogen-Deficient Conditions. PLoS ONE 8(5): e63666. doi:10.1371/journal.pone.0063666

Editor: Marie-Joelle Virolle, University Paris South, France

Received November 9, 2012; Accepted April 6, 2013; Published May 13, 2013

Copyright: (c) 2013 Setten et al. This is an open-access article distributed under the terms of the Creative Commons Attribution License, which permits unrestricted use, distribution, and reproduction in any medium, provided the original author and source are credited.

Funding: This work was supported by Instituto Nacional de Tecnología Agropecuaria (grant AEGR\#3425 to ADP) and Agencia Nacional de Promoción Científica y Tecnológica (grant PICT 2011-1325 to NA). The funders had no role in study design, data collection and analysis, decision to publish, or preparation of the manuscript.

Competing Interests: The authors have declared that no competing interests exist.

*E-mail: nayub@cnia.inta.gov.ar

\section{Introduction}

Nitrogen fertilizer application is an essential input for crop productivity in most regions of the world [1]. Reduction or elimination of this application will attenuate our dependence on fossil fuels as they are necessary for the production of nitrogen fertilizer. Both from health and environmental perspectives, the quality of ground water is adversely affected by nitrogen fertilization [2]. The interest in these problems has prompted the study of biological nitrogen fixation.

Nitrogen fixation is widespread among the Eubacteria and Archae domains [3]. These metabolically divergent and nonphylogenetic groups of microorganisms are collectively known as diazotophs; all of them possess a metallo-enzyme complex, the nitrogenase, which catalyzes one of the most remarkable chemical transformations in biological systems: the ATP-dependent reduction of atmospheric dinitrogen $\left(\mathrm{N}_{2}\right)$ to bioavailable ammonia [4]. In concordance with their exceptionally genetic diversity, diazotrophs have diverse lifestyles and several mechanisms to prevent $\mathrm{O}_{2}$ from damaging their nitrogenase. There are numerous freeliving strains of bacteria and archaea that are able to fix $\mathrm{N}_{2}$ under aerobic (e.g. Azotobacter vinelandii and Anabaena sp. strain PCG 7120) and anaerobic (e.g. Klebsiella pneumonia and Methanosarcina barkeri) conditions [5], [6], [7]. In addition, many strains of nitrogen-fixing Proteobacteria (e.g. Ensifer meliloti and Cupriavidus taiwanensis), Actinobacteria (e.g. Frankia alni and Auraticoccus monumenti) and Cyanobacteria (e.g. Nostoc punctiforme) can form symbiotic associations with legumes (e.g. soybean and alfalfa) and non-leguminous plants (e.g. shrubs and trees), providing the host with nitrogen-rich compounds [8], [9], [10], [11], [12], [13]. Unfortunately, this type of symbiosis is not observed in the most economically important crops (e.g. maize, rice and wheat) [14].

In this context, finding nitrogen-fixing inoculants to improve the production of important non-leguminous crops has often been touted as one of the ultimate goals of nitrogen fixation research [2], [15]. An approach to mitigate this difficulty is the use of endophytic diazotrophs. For example, Wood and coworkers have shown that $20 \%$ of wheat shoots nitrogen has been derived from Azospirillum brasilense nitrogen fixation under laboratory co-culture model [16]. Although, robust experiments have shown that endophytic diazotrophs (e.g. Acetobacter diazotrophicus and Pseudomonas stutzeri A1501) are able to fix nitrogen in the rhizosphere and can efficiently promote the growth of non-leguminous crops (e.g. Sugar cane and Rice), the potential efficiency and the mechanism of transfer of fixed nitrogen from these strains to their plant hosts are still uncertain [2], [14], [16], [17], [18], [19], [20], [21], [22], 
[23]. In fact, the transfer of fixed nitrogen from plant rootassociated diazotrophs to their non-legume hosts has been considered a key problem in the development of more effective nitrogen-fixing inoculants [2].

An approach complementary to the use of natural bacteria as inoculants could be the development of genetically modified organisms (GMOs) derived from plant growth-promoting rhizobacteria (PGPR). For instance, genetic engineering has been applied to increase the production of auxin and antifungal compounds in Pseudomonas, Azospirillum and Bacillus strains [24], [25], [26], [27], [28], [29], [30], [31]. Regarding genetic engineering for nitrogen fixation, some authors began to investigate the transfer of nif genes among different strains belonging to the phylum Proteobacteria. Some of these pioneer studies analyzed nif transfer between different strains of Klebsiella pneumonie via conjugation [32] and transduction [33]. Then, Dixon and Postgate demonstrated for the first time the transfer of a functional nitrogenase between two strains and empirically corroborated the nitrogen fixation in Escherichia coli expressing nif genes from Klebsiella pneumoniae by using the N15 isotope method [34]. Postgate and Kent also demonstrated that nif genes from $K$. pneumoniae can be transferred to Pseudomonas putida MT20-3 and that the recombinant Pseudomonas strain was able to express the nif genes and displayed nitrogenase activity quantified by acetylene reduction [35]. This result unambiguously confirmed that $K$. pneumoniae nif genes can be functionally expressed in an obligate aerobic microbe such as strains of the genus Pseudomonas. Additionally, it has been described that nodulation and nitrogen fixation genes can be transferred from symbiotic to nonsymbiotic rhizobia via mobile genetic elements [36], [37], [38], [39], [40], [41]. While all these studies have shown the transfer of natural mobile elements containing nif genes between different microorganisms, none has helped to develop inoculants.

Several works have shown bioinformatic evidence supporting horizontal transfer of nitrogenase among microorganisms. For example, phylogenetic analyses of nif genes have shown incongruence with rRNA data [42], [43], [44] and that nif genes are localized within mobile genetic elements, such as the nif genes found within the genomic islands, also named nitrogen fixation islands, on the chromosome of Pseudomonas stutzeri A1501 and Pseudomonas stutzeri DSM4166 [23], [45]. Nitrogen fixation is a rare feature in the genus Pseudomonas [46], [47] and the presence of nitrogen fixation islands within some strains belonging to this genus suggests (i) that Pseudomonas could be a favorable background for the expression of a heterologous nitrogenase and (ii) that the horizontal transfer of nitrogen fixation islands in Pseudomonas strains has occurred recently and that, then, all genes required for the expression of nitrogenase could be efficiently packaged within the nitrogen fixation islands of $P$. stutzeri A1501 and $P$. stutzeri DSM4166. The latter is supported by indirect evidence such as the global transcriptional analysis of nitrogen fixation in $P$. stutzeri A1501 [23], [48].

The aim of the present study was to develop a geneticengineering technique to obtain recombinant nitrogen-fixing bacteria. In the analysis of nif gene transfer performed in this work, the donor (i.e. Pseudomonas stutzeri A1501) and recipient (i.e. Pseudomonas protegens Pf-5, Pseudomonas putida KT2440, Pseudomonas veronii DSM11331, Pseudomonas taetrolens IAM1653, Pseudomonas balearica SP1402 and Pseudomonas stutzeri CGUG1 1256) strains were restricted to well-characterized species belonging to Pseudomonas sensu stricto [23], [46], [49], [50], [51], [52], [53], [54], [55], [56]. The key to constructing a recombinant vector containing all the genes necessary for expressing a functional nitrogenase was the use of $P$. stutzeri A1501 as the donor strain because this bacterium has nif genes co-localizated within the chromosome [23]. On the other hand, Pseudomonas protegens Pf-5 was selected as a recipient strain of nif genes because this bacterium is a biological control agent bacterium that lives in the rhizosphere of a wide variety of plant species and is able to persist and compete with native soil microbes [49], [57], [58]. In this paper, we report on the transformation of $P$. protegens $\mathrm{Pf}-5$ with the nitrogen fixation island from $P$. stutzeri A1501 via the recombinant cosmid (X940). The recombinant strain Pf-5 X940 displayed high nitrogenase activity, released significant quantities of ammonium to the medium and promote the growth of Arabidopsis thaliana, Medicago sativa (alfalfa), Schenodorus arundinaceus (tall fescue) and Zea mays (maize) under nitrogen deficient-conditions. The characterization of Pseudomonas putida KT2440, Pseudomonas veronii DSM11331, Pseudomonas taetrolens IAM1653, Pseudomonas balearica SP1402 and Pseudomonas stutzeri CCUG11256 transformed with cosmid X940 suggests that the genetic engineering strategy to obtain nitrogen-fixing strains is not limited to $P$. protegens $\mathrm{Pf}-5$ and can be extrapolated to other bacteria. Hence, this work opens a new perspective for inoculants biotechnology.

\section{Materials and Methods}

\section{Bacterial Strains}

The strains used in this study were Pseudomonas protegens Pf-5 [50], [51], Pseudomonas stutzeri A1501 [52], Pseudomonas putida KT2440 [53], Pseudomonas veronii DSM11331 [54], Pseudomonas taetrolens IAM1653 [55], Pseudomonas balearica SP1402 and Pseudomonas stutzeri GCUG11256 [56].

\section{Recombinant Strain Construction}

Two 255-bp fragments from Pseudomonas stutzeri A1501 (accession number: CP000304) intergenic regions PST_1306PST_1307 and PST_1312-PST_1313 were obtained by colony PCR amplification using A1-A2 and A3-A4 primers (Table S1), respectively. The PST_1306-PST_1307 amplification fragment

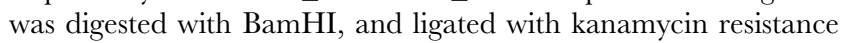
gene (kan) obtained from plasmid pUC4K (X06404) cut with BamHI. The PST_1312-PST_1313 amplification fragment was digested with SalI and cloned into the recombinant plasmid. The resulting plasmid, which does not replicate in Pseudomonas, was introduced by transformation into competent cells of A1501 prepared as previously [59]. Transformants were selected by plating on LB agar containing $50 \mu \mathrm{g} / \mathrm{ml}$ of kanamycin. A single kanamycin colony was chosen and named A1501C. The double recombinant event in strain A1501C was checked by PCR as previously reported [59] and its ability to fix nitrogen was confirmed by growth in $\mathrm{L}$ medium without $\left(\mathrm{NH}_{4}\right)_{2} \mathrm{SO}_{4}$.

The SuperCos1 vector (accession number: M99566.1) was digested with AvaI and religated to eliminate the pSV40-neoR reporter cassette. Next, the resulting vector (named pSC2) was digested with $\mathrm{XbaI}$, dephosphorylated, and digested with BamHI, and then ligated with the DNA fragment obtained from A1501C cut with MboI. The genomic library was screened for the presence of the kanamycin resistance gene, using Escherichia coli grown on LB medium containing kanamycin $50 \mu \mathrm{g} / \mathrm{ml}$ and ampicillin $100 \mu \mathrm{g} / \mathrm{ml}$. One recombinant cosmid, named X940, obtained from the genomic library of $\mathrm{A} 1501 \mathrm{C}$ containing nif genes was sequenced by primer walking (Dataset S1, Figure S1). The X940 cosmid was introduced by transformation into competent cells of P. protegens Pf-5, Pseudomonas putida KT2440, Pseudomonas veronii DSM11331, Pseudomonas taetrolens IAM1653, Pseudomonas balearica SP1402 and Pseudomonas stutzeri GCUG11256, prepared as previously described [59]. Transformants were selected by plating 


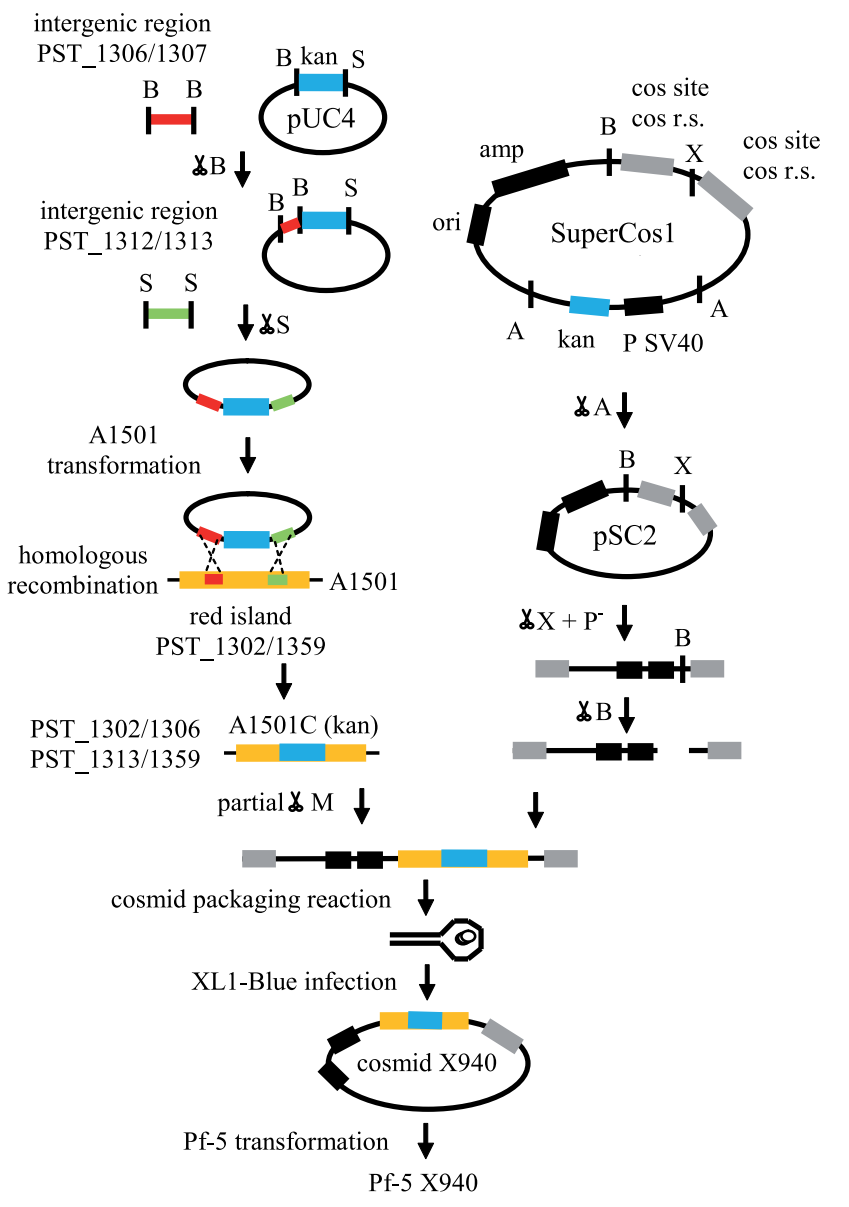

Figure 1. General scheme of the construction of cosmid X940. Pseudomonas protegens Pf-5 (Pf-5), Pseudomonas stutzeri A1501 (A1501), kanamycin resistance gene (kan), ampicillin resistance gene (amp), BamHI (B), Sall (S), Xbal (X), Mbol (M), Aval (A), dephosphorylation ( $\mathrm{P}^{-}$) are shown.

doi:10.1371/journal.pone.0063666.g001

on LB agar containing $50 \mu \mathrm{g} / \mathrm{ml}$ of kanamycin. The recombinant strains containing the cosmid X940 were named Pf-5 X940, KT2440 X940, DSM11331 X940, IAM1653 X940, SP1402 X940 and CGUG11256 X940.

Plasmid pENZO carrying the PST1307-PST1312 region of Pseudomonas stutzeri A1501 was constructed by cloning a $6.23 \mathrm{~kb}$ PCR amplification fragment using p07 and p13 primers (Table S1) into pBBR1MCS-3 (accession number: U25059) digested with SmaI. Conjugation of Pseudomonas protegenes Pf-5 X940 with Escherichia coli S17-1 harboring pENZO plasmid was performed on mineral salts medium plates according to [59]. The resulting recombinant strain derived from Pf-5 and containing cosmid X940 and pENZO plasmid was named Pf-5 X940(2).

To corroborate the presence of the nif genes within the recombinant Pseudomonas strains, we performed PCR assays (Figure S2). Genomic DNA was isolated from overnight cultures using Wizard Genomic DNA Purification Kit (\#A1120, Promega, USA). For the PGR assays, the 950-bp fragments of the nifH gene were obtained by PCR amplification using $\mathrm{N} 1$ and $\mathrm{N} 2$ primers (Table S1) and a program of 34 cycles of $94^{\circ} \mathrm{C}$ for $1 \mathrm{~min}, 56^{\circ} \mathrm{C}$ for $30 \mathrm{~s}$ and $72^{\circ} \mathrm{C}$ for $1 \mathrm{~min}$ and a final cycle of $72^{\circ} \mathrm{C}$ for $10 \mathrm{~min}$.

To study the insertion of X940 cosmid within Pf-5, we performed a genomic walking assay [59] using 2a, 2b, 59a and $59 \mathrm{~b}$ primers (Table $\mathrm{S} 1$ ). The further study this insertion, a
Southern blot assay was carried out. For the last study, a 2-kb digoxigenin-labeled DNA fragment within the PST1302PST1306 region was generated by PCR by using the PCR DIG probe synthesis kit (Roche) and used as a probe. PCR amplification was performed under standard conditions with a program of 34 cycles of $94^{\circ} \mathrm{C}$ for $1 \mathrm{~min}, 50^{\circ} \mathrm{C}$ for $30 \mathrm{~s}$ and $72^{\circ} \mathrm{C}$ for $2.5 \mathrm{~min}$ and a final cycle of $72^{\circ} \mathrm{C}$ for $10 \mathrm{~min}$. Digoxigenin labeled PCR products were generated for use as probes using oligonucleotides PST1302up and PST1306low (Table S1). Genomic DNA was cut using XhoI or HindIII and DNA fragments in gels were then transferred to a positively charged Nylon membrane (Roche). Nylon membranes were crosslinked and then used for hybridization with DIG-labeled PST1302-PST1306 probe. Prehybridization and hybridization was carried out according to the manufacturer's instructions (Roche).

\section{Bacterial Growth under Nitrogen-limiting Conditions}

Cultures were performed in 125-ml Erlenmeyer flasks containing $25 \mathrm{ml}$ of $\mathrm{L}$ medium, incubated at $28^{\circ} \mathrm{C}$ with shaking

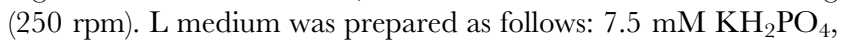
$17.22 \mathrm{mM} \mathrm{K}_{2} \mathrm{HPO}_{4}, 3.42 \mathrm{mM} \mathrm{NaCl}, 7.57 \mathrm{mM}\left(\mathrm{NH}_{4}\right)_{2} \mathrm{SO}_{4}$, $2 \mathrm{mM} \mathrm{MgSO}_{4} 7 \mathrm{H}_{2} \mathrm{O}, 3.7 \mathrm{mM} \mathrm{FeCl}_{3} 6 \mathrm{H}_{2} \mathrm{O}, 0.1 \mathrm{mM} \mathrm{CuCl}_{2} 2$ $\mathrm{H}_{2} \mathrm{O}, 0.1 \mathrm{mM} \mathrm{ZnSO} 47 \mathrm{H}_{2} \mathrm{O}, 0.73 \mathrm{mM} \mathrm{MnCl}{ }_{2} \mathrm{H}_{2} \mathrm{O}, 1 \mathrm{mM}$ $\mathrm{CaCl}_{2} 2 \mathrm{H}_{2} \mathrm{O}, 0.21 \mathrm{mM} \mathrm{NaMoO}, 3.4 \mathrm{mM}$ citric acid, $28 \mathrm{mM}$ glucose, $100 \mathrm{mg} / \mathrm{l}$ yeast extract, $\mathrm{pH}=7$. To test growth under nitrogen-limiting conditions in aerobic (Erlenmeyer covered with parafilm) and micro-aerobic (Erlenmeyer flasks with plastic screw caps) environments, overnight cultures grown in $\mathrm{L}$ medium were used to inoculate $\mathrm{L}$ medium with or without $\left(\mathrm{NH}_{4}\right)_{2} \mathrm{SO}_{4}$. All cultures were adjusted to an initial optical density (OD580 nm) of 0.05 (around $10^{6} \mathrm{CFU} / \mathrm{ml}$ ). The preculture was washed twice in $\mathrm{L}$ medium without nitrogen sources and then used to inoculate culture. Bacterial growth was spectrophotometrically monitored at OD580 $\mathrm{nm}$ and colony forming units (CFU) counted at $48 \mathrm{~h}$. The identities of the strains were confirmed by PCR colony and subsequently sequenced, using E9F-E1541R, GyrFw-GyrRv and nifA-p1 nifA-p2 primers for 16S rRNA, DNA gyrase and nifA genes, respectively [60], [61], [62].

\section{Nitrogenase Activity and Ammonium Concentrations in the Medium}

Nitrogenase activity was evaluated according to [52] with slight modifications. Bacterial cells from an overnight culture in LB medium containing $50 \mathrm{mM}$ glucose were centrifuged and resuspended in a 50-ml flask containing $10 \mathrm{ml} \mathrm{N}$-free L medium (nitrogen fixation condition) or nitrogen-rich media such as $\mathrm{L}$ medium (nitrogen excess conditions) supplemented with $100 \mathrm{mM}$ glucose, at an OD580 $\mathrm{nm}$ of 0.1 . The suspension was incubated for $8 \mathrm{~h}$ at $28^{\circ} \mathrm{C}$ with shaking under an argon atmosphere containing $1 \%$ oxygen and $10 \%$ acetylene. The ammonium assay was perfomed using the nitrogen fixation condition described to nitrogenase activity assay but argon was changed for dinitrogen. Ammonium concentrations in the medium were measured by withdrawing a small sample, removing the cells by centrifugation, and assaying the supernatant by the indophenol method described previously [63]. The ethylene production was determined by gas chromatography according to [64] and protein content was determined by the Bradford method [65].

\section{Inoculation Tests}

For the inoculation assay, Columbia-0 Arabidopsis thaliana, Schenodorus arundinaceus (Festuca Alta Gentos), Medicago sativa (alfalfa Forage Genetics 969) and Zea mays (maize Pannar Pan6326 RRZ) 

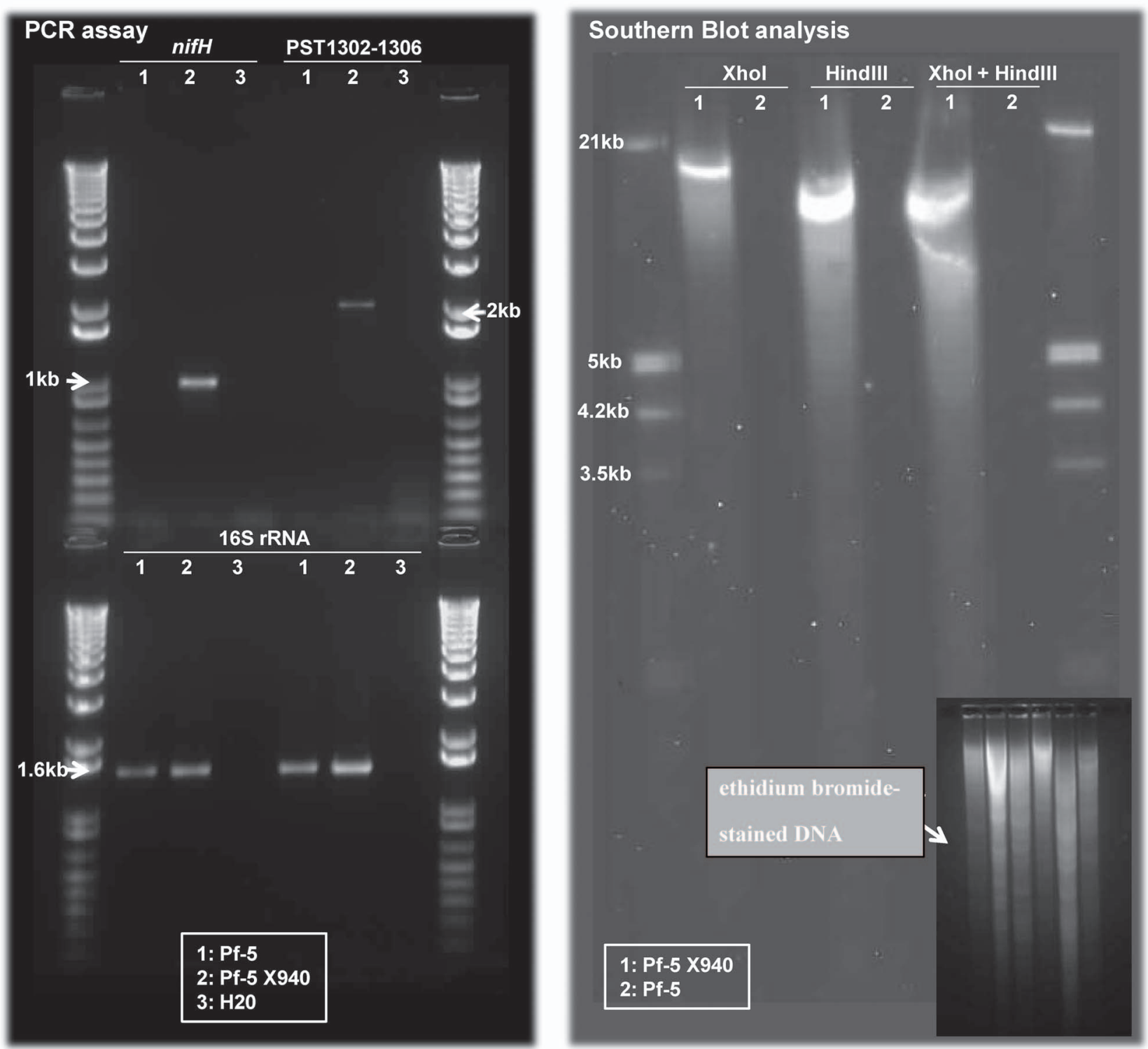

Figure 2. PCR and Southern blot analyses of genomic DNA from the Pf-5 X940 strain carrying the nifH gene and the PST1302PST1306 region. PCR marker: 1 Kb Plus DNA Ladder (INVITROGEN). Southern blot marker: Dig marker III (Roche). doi:10.1371/journal.pone.0063666.g002

seeds were surface-sterilized and vernalized for 5 days at $4^{\circ} \mathrm{C}$ in darkness. Then, plants were incubated in a growth chamber at $23^{\circ} \mathrm{C}$ under light/dark cycles of $16 \mathrm{~h} / 8 \mathrm{~h}$, with light intensities of $150 \mu \mathrm{mol} \mathrm{m} \mathrm{m}^{-2} \mathrm{sec}^{-1}$, in cultures containing a mixture of peat, perlite and vermiculite $(1: 1: 1 \mathrm{v} / \mathrm{v})$, a mixture of perlite and vermiculite $(1: 1 \mathrm{v} / \mathrm{v}), 100 \%$ vermiculite or a mixture of perlite and soil $(1: 4 \mathrm{v} / \mathrm{v})$, respectively. Arabidopsis, tall fescue and alfalfa plants were grown in INTA13 medium $\left(0.88 \mathrm{mM} \mathrm{CaCl}_{2} 2 \mathrm{H}_{2} \mathrm{O}\right.$, $1 \mathrm{mM} \mathrm{MgSO} 47 \mathrm{H}_{2} \mathrm{O}, 1 \mathrm{mM} \mathrm{Na} \mathrm{HPO}_{4}, 0.73 \mathrm{mM} \mathrm{KH_{2 }} \mathrm{PO}_{4}$, $4.13 \mu \mathrm{M} \mathrm{Na}_{2} \mathrm{MoO}_{4} 2 \mathrm{H}_{2} \mathrm{O}, 3.55 \mu \mathrm{M} \mathrm{MnSO}_{4} \mathrm{H}_{2} \mathrm{O}, 4 \mu \mathrm{M} \mathrm{CuSO}_{4}$ $5 \mathrm{H}_{2} \mathrm{O}, 3.48 \mu \mathrm{M} \mathrm{ZnSO}{ }_{4} 7 \mathrm{H}_{2} \mathrm{O}, 16.17 \mu \mathrm{M} \mathrm{H}_{3} \mathrm{BO}_{3}, 14.8 \mu \mathrm{M}$ $\mathrm{FeCl}_{3} 6 \mathrm{H}_{2} \mathrm{O}, \mathrm{pH}=6.5$ ) with or without $1 \mathrm{mM} \mathrm{Ca}\left(\mathrm{NO}_{3}\right)_{2} 4 \mathrm{H}_{2} \mathrm{O}$ as nitrogen source for 40 days. Each week a $0.5 \mathrm{ml}$ sample of hydroponic medium was taken and the ammonium was measured as described above. The trays and pots were sterilized with $70 \%$ ethanol. The substrate was sterilized by heat treatment $\left(350^{\circ} \mathrm{C}\right.$ for 30 minutes) and washed twice with sterile distilled water. Maize plants were irrigated with water for 30 days. To assay maize growth under nitrogen excess conditions, soil was supplemented with $400 \mathrm{mg} \mathrm{NH} \mathrm{SO}_{4}$. Arabidopsis, tall fescue and alfalfa plants were inoculated after vernalization either with wild-type (Pf-5) or recombinant bacteria (Pf-5 X940) prepared as follows: $1 \mathrm{ml}$ of overnight cultures grown at $28^{\circ} \mathrm{C}$ in $\mathrm{L}$ medium was centrifuged and then resuspended in $1 \mathrm{ml}$ of saline solution. Then, $200 \mu \mathrm{l}$ of the bacterial solution $\left(810^{8}-210^{9}\right.$ colony forming units $\left.(\mathrm{CFU}) / \mathrm{ml}\right)$ was used to inoculate plants in pots $(1 \mathrm{~L})$. We recovered the strains after the inoculation trials. We also detected no contamination in hydroponic medium assays. The identities of the strains were established by PCR colony and subsequently sequenced using E9F-E1541R primers for 16S rRNA gene [62]. In the case of maize inoculation, $2 \mathrm{ml}$ of the bacterial solution was used to inoculate pots of $10 \mathrm{~L}$. Values represent mean+SEM, $n=3$ independent experiments. Each experiment had 12 plants. Thus, we evaluated 36 plants for each treatment. Soil mineral-N 

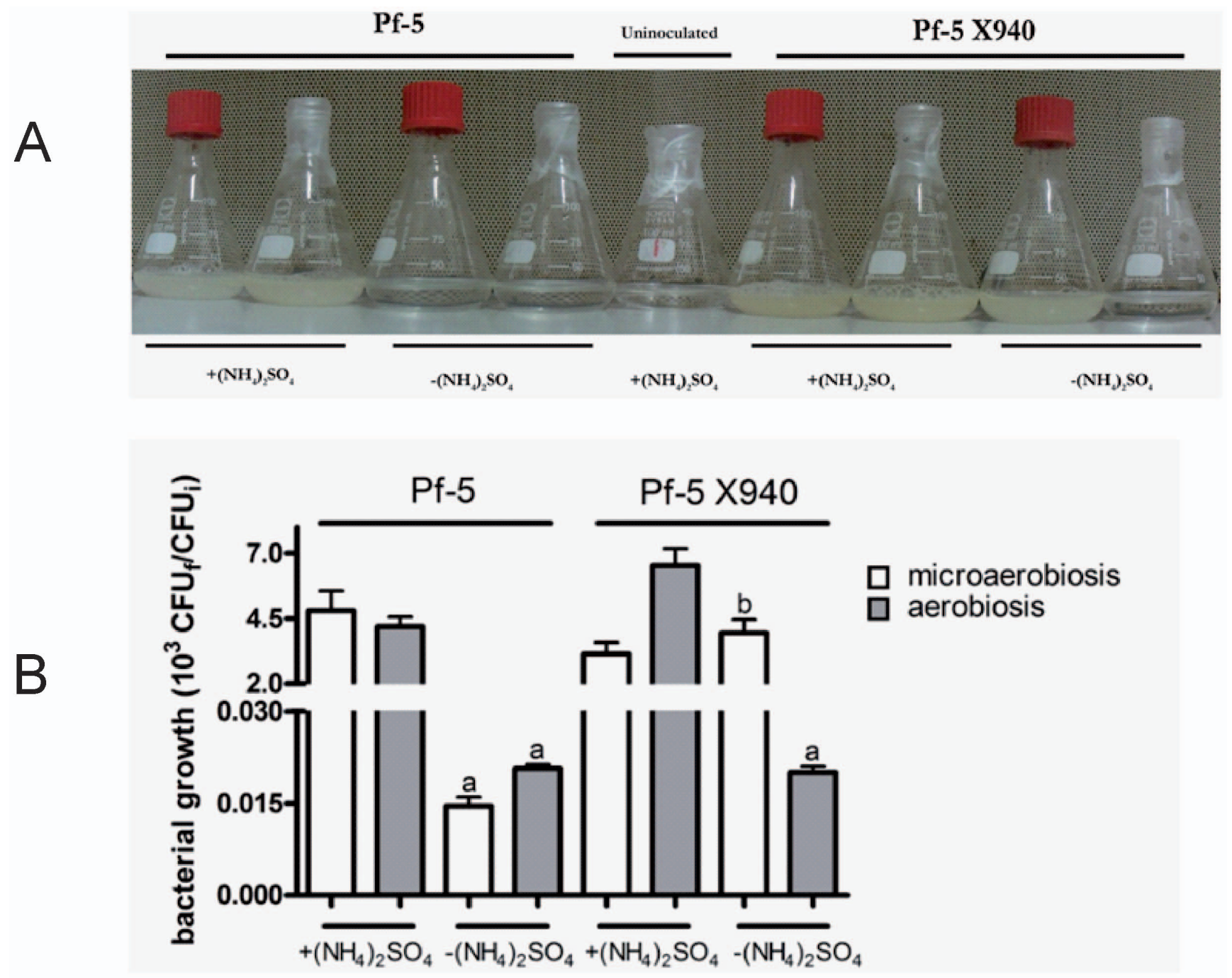

Figure 3. Effect of the transformation of Pseudomonas Pf-5 with cosmid X940. We analyzed the growth of Pf-5 and Pf-5 X940 in L medium with and without nitrogen under microaerobiotic (Erlenmeyers with lid) and aerobic (Erlenmayers sealed with parafilm) conditions by means of turbidity (a) and the relationship between the CFU (colony-forming units) at the beginning and at the end of the experiment (b). The statistical analysis was carried out with ANOVA followed by Tukey's contrast test. The letters correspond to the treatments compared. The same letters correspond to non-significant differences. (a) and (b) showed significant differences with $p<0.001$.

doi:10.1371/journal.pone.0063666.g003

determinations were performed in Laboratorios Fox (http://www. foxlab.com.ar/). $\mathrm{NH}_{4}{ }^{+}$was extracted with $1 \mathrm{M} \mathrm{KCl}$ (soil:extractant ratio 1:4) and $\mathrm{NO}_{3}{ }^{-}$with water (soil: extractant ratio 1:2.5) at $250 \mathrm{rpm}$ for $1 \mathrm{~h}$. After centrifuging (4000 rpm for $30 \mathrm{~min}$ ), supernatants were filtered and mineral-N was determined. $\mathrm{NH}_{4}{ }^{+}-\mathrm{N}$ and $\mathrm{NO}_{3}{ }^{-} \mathrm{N}$ were quantitatively determined by colorimetric methods (AQAassay, GTLab, Argentina) based on two different sodium salicylate reactions [66], [67]. Absorbance was measured in a DR6000 spectrophotometer (Hach). We evaluated the persistence of Pf-5 and Pf-5 X940 in sterile $\left(121^{\circ} \mathrm{C}, 1 \mathrm{~atm}\right.$, $20 \mathrm{~min}$ ) soil microcosms (50 $\mathrm{g}$ of dry soil) prepared as previously described [68].

\section{RT-PCR Analysis}

Total RNA was extracted by using the RNeasy Mini kit (Qiagen) and treated with DNaseI. cDNA was obtained using random hexamers (Promega) and AMV Reverse Transcriptase M9004 (Promega) following the manufacturer's instructions. For PGR amplification, $1 \mu \mathrm{l}$ of RT reaction was used. The PGR reactions were carried out in $25 \mu \mathrm{l}$ with $0.5 \mu \mathrm{M}$ of each primer [69]. RT-PCR experiments were performed according to [70] with very slight modifications. PCR was performed by using $1 \mathrm{U}$ Taq Platinum ADN polymerase (Invitrogen), buffer Taq Platinum 10X, $0.25 \mathrm{mM}$ dNTP, $0.4 \mathrm{mM}$ primers and $2 \mathrm{mM} \mathrm{MgCl}_{2}$ with Opticon2 (MJ Research), according to the manufacturer's instruction. Table $\mathrm{S} 1$ showed primers used for PCR. PCR conditions comprised: 1 cycle at $94^{\circ} \mathrm{C}$ for $3 \mathrm{~min}, 34$ cycles of $94^{\circ} \mathrm{C}$ for $45 \mathrm{~s}, 59.1^{\circ} \mathrm{C}$ for $1 \mathrm{~min}$ and $72^{\circ} \mathrm{C}$ for $1 \mathrm{~min}$. The expression of nifA, nifB and nifH genes was normalized to the expression of housekeeping gene gap-1 [71]. This analysis was performed three hours after incubation in $\mathrm{L}$ medium. The efficiency of primer binding was determined by linear regression by plotting the cycle threshold $\left(\mathrm{C}_{\mathrm{T}}\right)$ value versus the $\log$ of the cDNA dilution [72]. qPCR experiments were independently performed three times, with comparable results. The three PCR reactions were carried -out in duplicate. 
A
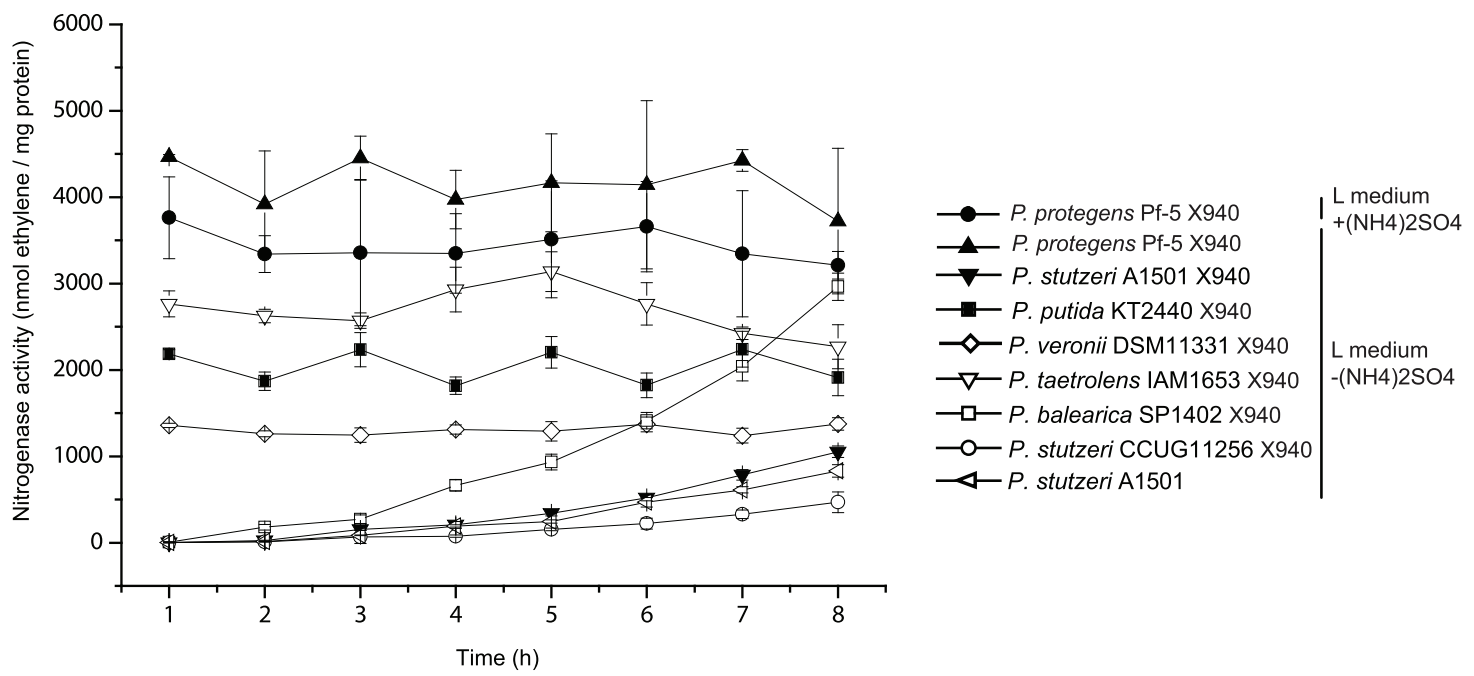

B
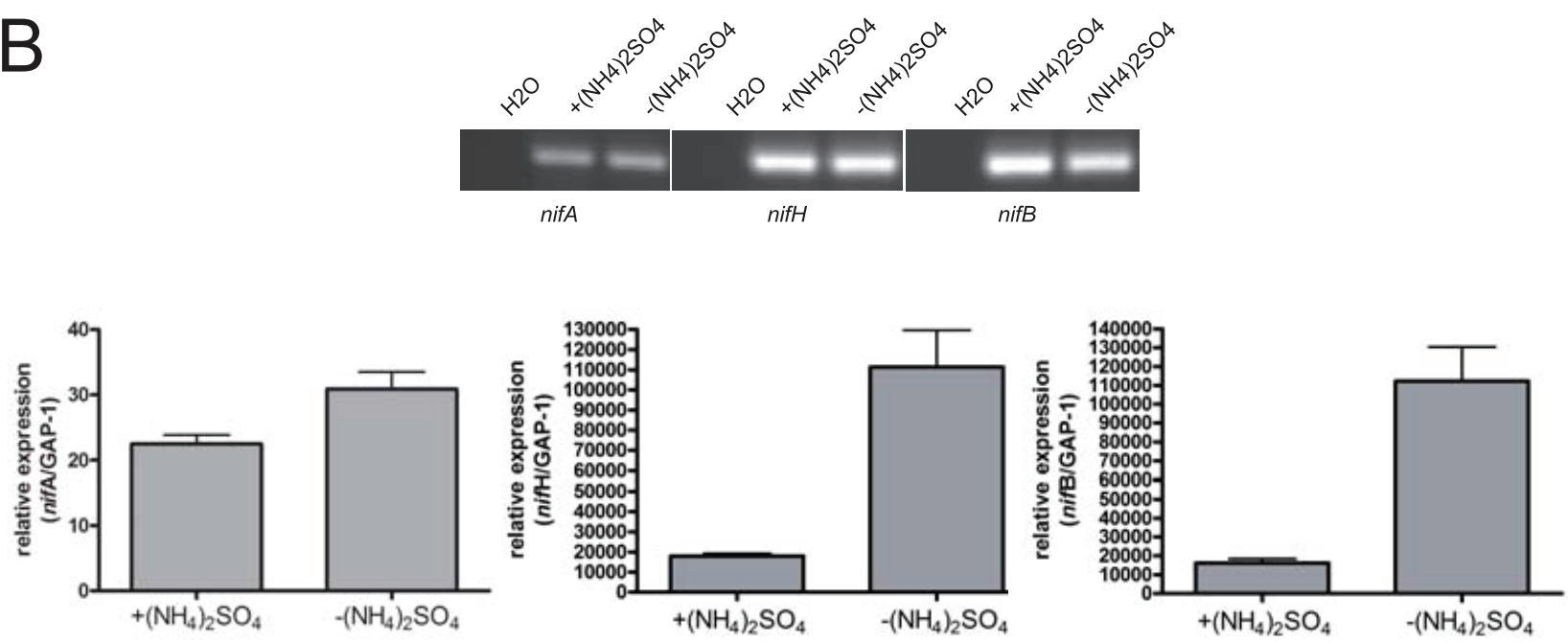

Pf-5 X940 L medium

C

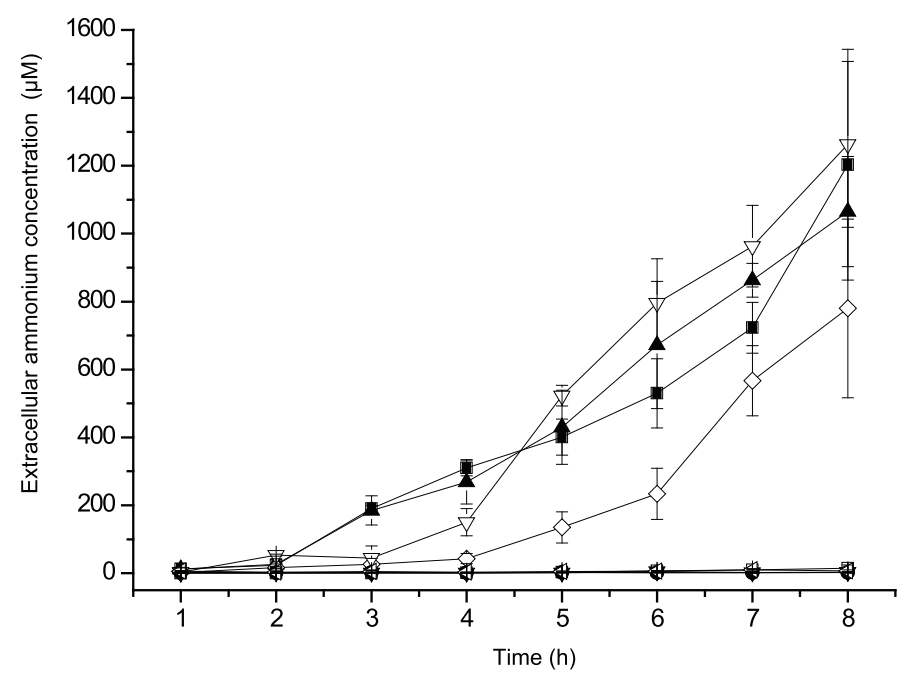

- $\_$P. protegens Pf-5 X940

- P. stutzeri A1501 X940

$\longrightarrow$ P. putida KT2440 X940

$\checkmark P$. veronii DSM11331 X940

$\rightarrow-P$. taetrolens IAM1653 X940

$\longrightarrow$ - $P$. balearica SP1402 X940

-O- P. stutzeri CCUG11256 X940

- P. stutzeri A1501

- P. protegens Pf-5 
Figure 4. Adaptation of nitrogenase to new bacteria (a) nitrogenase activity, (b) nif gene expression and (c) ammonium production of recombinant Pseudomonas containing X940 cosmid. Nitrogenase activity and extracellular ammonium concentration values are the mean \pm SEM of three independent measurements. RT-PCR and Real-time RT-PCR (nifA, nifH and nifB) studies of nif gene expression in Pf-5 X940 in the presence $\left(+\left(\mathrm{NH}_{4}\right)_{2} \mathrm{SO}_{4}\right)$ or absence $\left(-\left(\mathrm{NH}_{4}\right)_{2} \mathrm{SO}_{4}\right)$ of nitrogen. Transcript abundance for nifA, nifH and nifB genes was normalized to that for GAP1 gene. Values represent media+SEM, $\mathrm{n}=3$ independent experiments. doi:10.1371/journal.pone.00636 $\overline{6} 6.9004$

\section{Homology Modeling of Pseudomonas stutzeri A1501 Nitrogenase}

Based on the amino-acid sequence of Pseudomonas stutzeri A1501 nitrogenase, the prediction of its unknown three-dimensional structure, chains $\mathrm{A}$ and $\mathrm{B}$, was performed using Swiss-Model homology modeling server [73], as previously reported by Mozzicafreddo [74]. In particular, we used Swiss-Pdb Viewer (version 4.01) to create the project files submitted to the server with default parameters settings (BLAST search $\mathrm{P}$ value $<0.00001$ and global degree of sequence identity SIM $>25 \%$ ). Moreover, $\operatorname{lm} \operatorname{lnA}$ and $1 \mathrm{~m} \operatorname{lnB}$ from Azotobacter vinelandii [75], sharing $91 \%$ sequence identity with respect to $P$. stutzeri, were selected as structure templates, producing a high-accuracy comparative model (sequence identity $>50 \%$ ). Nitrogenase query sequences (A4VJ7 1 for chain A and A4VJ72 for chain B) were obtained from UniProt Knowledgebase (http://beta.uniprot.org/).

\section{Results}

Introduction of nif Genes into Pseudomonas protegens Pf5

Transfer of the nif genes into Pseudomonas protegens Pf-5 required several steps of genetic engineering (Figure 1). First, we performed a mutagenesis directed over Pseudomonas stutzeri A1501, where the genomic region PST1307-PST1312 was replaced by a kanamycin cassette, resulting in the recombinant strain A1501C. Then, we constructed a recombinant cosmid (pSC2) from SuperCos1 cosmid. pSC2 was identical to the original one, but suffered a deletion in the region that encodes the gene for kanamycin resistance. pSC2 was used to produce a genomic library of the A1501C. After a selection on kanamycin (nif region) and ampicillin (vector), we selected X940 cosmid for having 52 genes corresponding to the PST1302-PST1306 and PST1313-PST1359 regions. Cosmid X940, which does not replicate in Pseudomonas, was introduced by transformation into $P$. protegens $\mathrm{Pf}-5$. The recombinant $P$. protegens $\mathrm{Pf}-5$ containing cosmid X940 was named Pf-5 X940. Genomic PCR analysis confirmed the presence of the nifH gene in the Pf-5 X940 strain and the Southern blot assay showed that the recombinant strain has only one copy of cosmid X940 inserted within its genome (Figure 2). Genome walking assays demonstrated that this insertion is within the PFL_0092PFL_0093 intergenic region (Figure S3).

\section{Growth of Pf-5 X940 under Nitrogen Limited Conditions}

To study the functionality of the heterologous nitrogenase complex, the growth of both wild-type (Pf-5) and recombinant (Pf5 X940) bacteria was evaluated by turbidity of the culture medium (Figure 3a) and by counting colony forming units (CFU) (Figure 3b), for 48 hours in $\mathrm{L}$ medium either without nitrogen $\left(-\left(\mathrm{NH}_{4}\right)_{2} \mathrm{SO}_{4}\right)$ or supplemented with nitrogen $\left(+\left(\mathrm{NH}_{4}\right)_{2} \mathrm{SO}_{4}\right)$, in aerobiosis or microaerobiosis under laboratory conditions. During the first 24 hours, growth was observed only in the cultures supplemented with nitrogen (data not shown), whereas after 48 hours significant growth was also observed in the Pf-5 X940 bacterium in $\mathrm{L}$ medium without nitrogen under microaerobic conditions (Figure 3). This recombinant bacterium showed no significant growth in $\mathrm{L}$ medium without nitrogen in aerobic conditions (Table S2), suggesting that the heterologous nitrogenase complex was active only at low oxygen tension (Figure 3). Under microaerobiosis, the number of Pf-5 bacteria increased two-fold (probably due to a residual cell division), whereas the number of Pf-5 X940 bacteria increased more than three orders of magnitude (approximately 12 generations) in L medium without nitrogen (Figure 3b), suggesting that the recombinant strain could use molecular nitrogen $\left(\mathrm{N}_{2}\right)$ as nitrogen source.

\section{Nitrogenase Activity and nif Genes Expression of Pf-5 X940}

To characterize the heterologous nitrogenase complex, we analysed nitrogenase activity in Pf-5 X940 (PST1302-PST1306 and PST1313-PST1359) in L medium in the presence or absence of nitrogen under microaerobiosis. As expected, no nitrogenase activity was observed in wild-type bacteria Pf-5 $(<1 \mathrm{nmol}$ ethylene/h/mg protein). In contrast, the recombinant bacteria containing nif genes showed nitrogenase activity (Figure 4a). More importantly, Pf-5 X940 displayed an uncommon nitrogenase activity phenotype. First, nitrogenase activity was not significantly repressed in this recombinant strain in medium containing ammonium (Figure 4a). Second, Pf-5 X940 did not show a typical desrepression phenotype observed in natural nitrogen-fixing strains such as A1501 in L medium in the absence of ammonium but displayed a constitutive nitrogenase activity (Figure 4a). In concordance with this unusual phenotype, we could detect the expression of genes coding for positive transcriptional regulator (nifA), structural (nifH) and biosynthetic (nifB) components of the nitrogenase complex in L medium supplemented with ammonium (Figure 4b), suggesting that Pf-5 context was unable to completely repress the transcription of nif genes under nitrogen excess conditions. However, the addition of ammonium had a negative effect on the expression of nif genes in Pf-5 X940 (Figure 4b), suggesting that this recombinant strain could retain at least some of the negative transcriptional regulation under nitrogen excess conditions. In addition, constitutive nitrogenase activity in the recombinant strain was associated with high ammonium production in the L medium without nitrogen (Figure 4c). Moreover, the recombinant strain Pf-5 X940(2) containing the PST1302PST1359 nif region displayed a nitrogenase activity, an ammonium production and a nif gene expression pattern similar to Pf-5 X940 (Figure S4), suggesting that the PST1307-PST1312 region is not involved in adaptation of nif genes to the new host.

To assess whether it is possible to transfer to other strains the ability to fix nitrogen through the genetic engineering methodology developed in this work, we transformed the strains Pseudomonas putida KT2440, Pseudomonas veronii DSM1 1331, Pseudomonas taetrolens IAM1653, Pseudomonas balearica SP1402 and Pseudomonas stutzeri CCUG11256 with cosmid X940 (Figure S3). All strains showed nitrogenase activity (Figure 4a), suggesting that this methodology may have applications not restricted to the Pf-5 strain. More interestingly, we observed that some strains, such as $P$. balearica SP1402 X940 and P. stutzeri CGUG11256 X940, showed a classic desrepresion-pattern of nitrogenase activity as seen also in the control strain A1501, but other strains of this genus, such as $P$. putida KT2440 X940, P. veronii DSM11331 X940 and P. taetrolens IAM1653 X940 showed a nitrogenase activity pattern similar to 

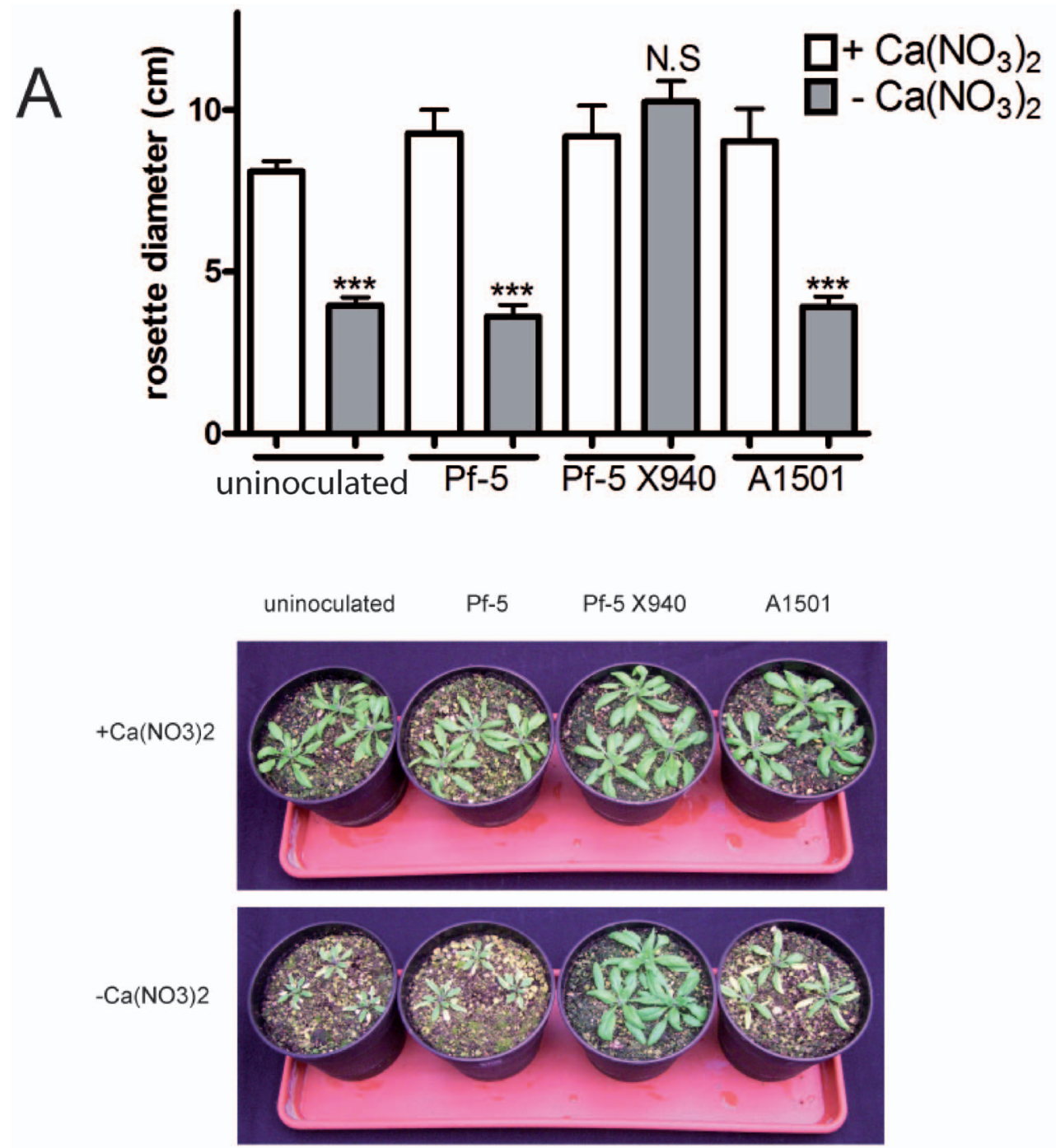

B

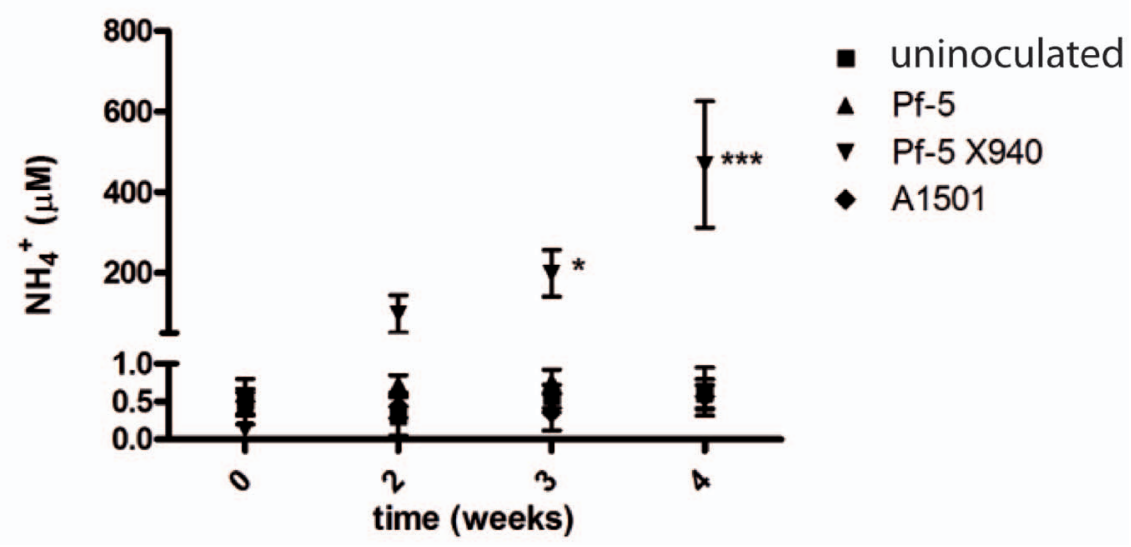

Figure 5. Effect of the inoculation with Pf-5 X940 on (a) Arabidopsis growth and (b) ammonium production. We analyzed the productivity (rosette diameter) and measured the ammonium in solid $\left(\mathrm{NH}_{4}{ }^{+}\right)$of Arabidopsis plants inoculated with A1501, Pf-5 and Pf-5 X940 in the presence $\left(+\mathrm{Ca}\left(\mathrm{NO}_{3}\right)_{2}\right)$ or absence $\left(-\mathrm{Ca}\left(\mathrm{NO}_{3}\right)_{2}\right)$ of nitrogen in the substrate. The statistical analysis was carried out with two-way ANOVA in the case of ammonium measurements or one-way ANOVA in the case of rosette diameter, followed by Tukey's multiple comparison tests in both cases. Comparisons were made between plants that received the same inoculation treatment in different conditions of nitrogen in the substrate $\left({ }^{* * *} p<0.001{ }^{* *} p<0.01\right.$ and $\left.{ }^{*} p<0.05\right)$. N.S: not significant.

doi:10.1371/journal.pone.0063666.g005 

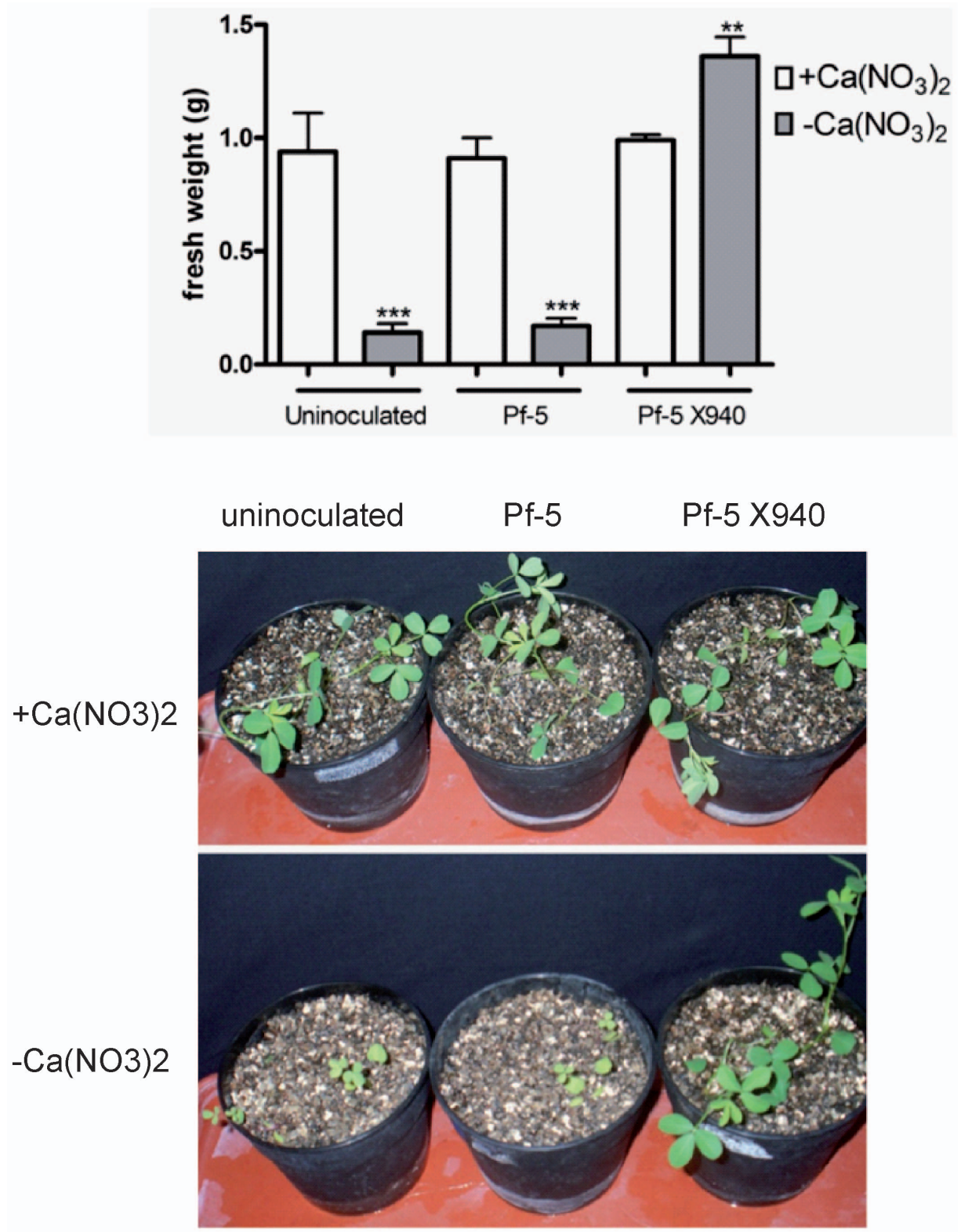

Figure 6. Effect of the inoculation with PF-5 X940 on alfalfa growth. We analyzed the productivity (fresh weight) of plants inoculated with Pf5 and Pf-5 X940 in the presence $\left(+\mathrm{Ca}\left(\mathrm{NO}_{3}\right)_{2}\right)$ or absence $\left(-\mathrm{Ca}\left(\mathrm{NO}_{3}\right)_{2}\right)$ of nitrogen in the substrate. The statistical analysis was carried out with ANOVA followed by Tukey's contrast test. Comparisons were made between plants that received the same inoculation treatment in different conditions of nitrogen in the substrate $\left(* * p<0.01\right.$ and $\left.{ }^{* * *} p<0.001\right)$. doi:10.1371/journal.pone.0063666.g006

that observed in Pf-5 X940 (Figure 4a). In association with constitutive nitrogenase activity, $P$. putida KT2440 X940, $P$. veronii DSM11331X940 and $P$. taetrolens IAM1653 X940 showed high ammonium production in the $\mathrm{L}$ medium without nitrogen (Figure 4c). These results strongly suggest that the adaptation of the nitrogenase complex depends on the genome context.

Effect of Inoculation with Pf-5 X940 on Plant Productivity

To analyze the potential impact of the Pf-5 X940, we assessed the effect of the inoculation with Pf-5 X940 on the growth of Arabidopsis (Figure 5). This plant was grown in hydroponics and irrigated with the minimal medium called "INTA13" either without nitrogen $\left(-\mathrm{Ca}\left(\mathrm{NO}_{3}\right)_{2}\right)$ or supplemented with nitrogen
$\left(+\mathrm{Ca}\left(\mathrm{NO}_{3}\right)_{2}\right)$, inoculated with Pf-5, Pf-5 X940, A1501, or noninoculated (control).

After 40 days of growth, the non-inoculated plants and plants inoculated with the wild-type strains showed a significantly lower productivity in INTA13 medium without nitrogen than in this same medium supplemented with nitrogen (Figure 5A). This growth reduction in the medium without nitrogen was completely reversed by inoculation with the recombinant bacterium Pf- 5 X940 (Figure 5A). This reversion was positively associated with the ammonium levels (Figure 5B), suggesting that the beneficial effect of Pf- 5 X940 inoculation could be attributed to the production and excretion of a high amount of ammonium to the medium. No significant differences in plant growth were observed with three different inoculants when the medium was supplemented with 


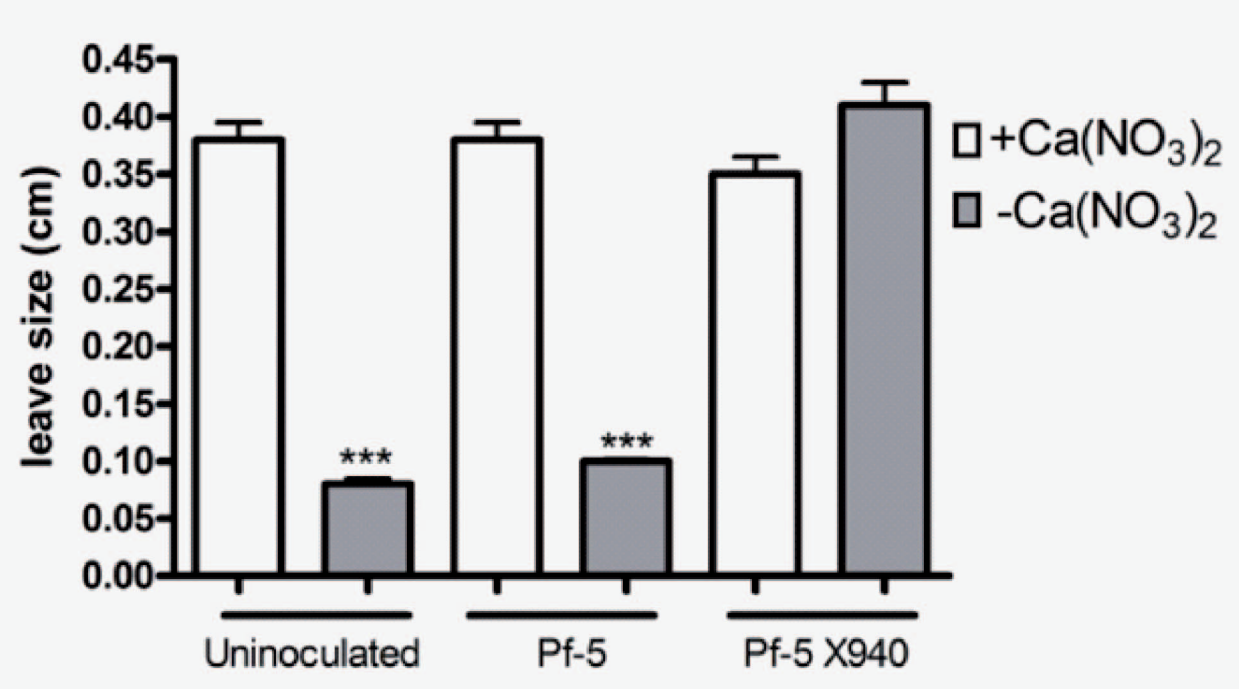

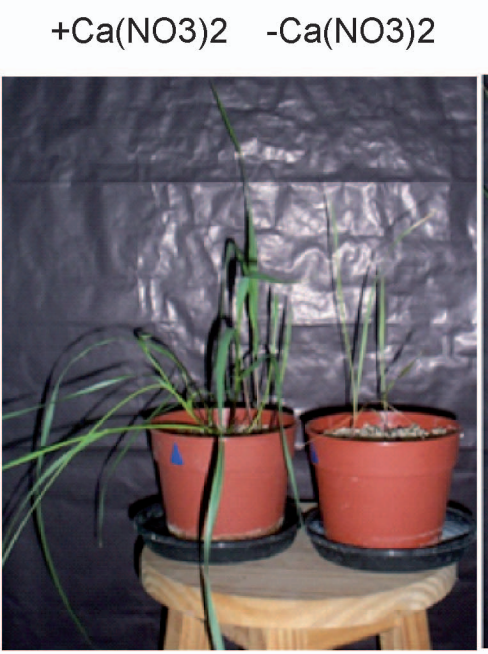

uninoculated

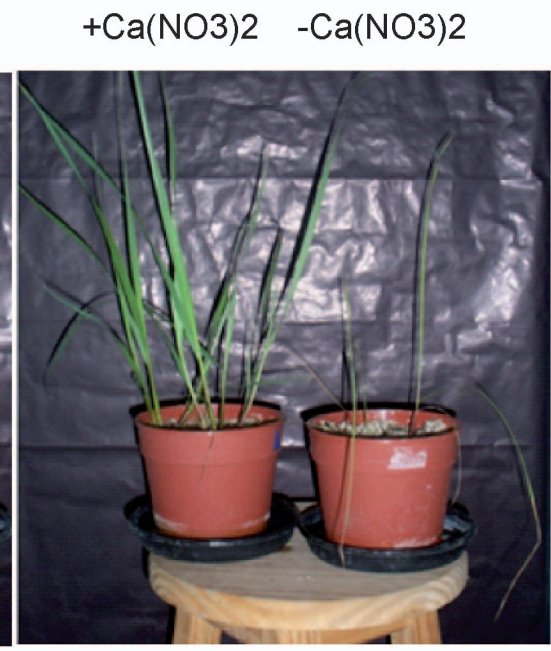

Pf-5
$+\mathrm{Ca}(\mathrm{NO} 3) 2 \quad-\mathrm{Ca}(\mathrm{NO} 3) 2$

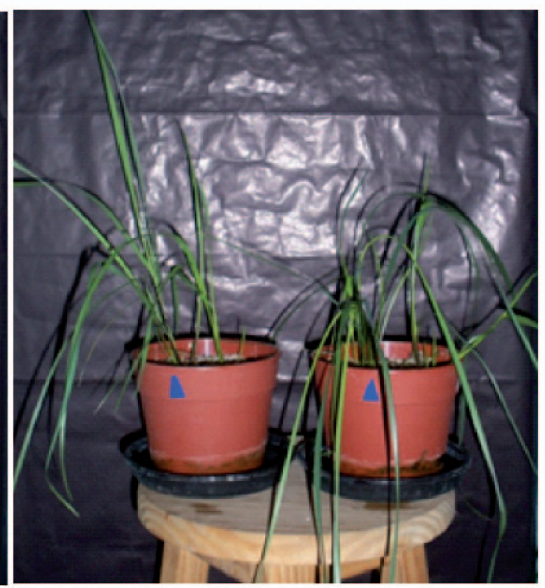

Pf-5 X940

Figure 7. Effect of the inoculation with PF-5 X940 on tall fescue growth. We analyzed the productivity (first leaf width) of plants inoculated with Pf-5 and Pf-5 X940 in the presence $\left(+\mathrm{Ca}\left(\mathrm{NO}_{3}\right)_{2}\right)$ or absence $\left(-\mathrm{Ca}\left(\mathrm{NO}_{3}\right)_{2}\right)$ of nitrogen in the substrate. The statistical analysis was carried out with ANOVA followed by Tukey's contrast test. Comparisons were made between plants that received the same inoculation treatment in different conditions of nitrogen in the substrate ${ }^{* *} p<0.01$ and $\left.{ }^{*} p<0.05\right)$.

doi:10.1371/journal.pone.0063666.g007

nitrogen (Figure 5A). Similar positive effects of Pf-5 X940 inoculation were observed in two agronomicaly important plants, the dicotyledenous Medicago sativa (alfalfa) (Figure 6) and the monocotyledoneous Schenodorus arundinaceus (tall fescue) (Figure 7) under hydroponic conditions. Unexpectedly, the productivity of alfalfa inoculated with Pf-5 X940 and grown in INTA13 medium without nitrogen was even significantly greater than that found in non-inoculated plants and plants inoculated with Pf-5 and grown in INTA13 with nitrogen (Figure 6).

The effect of Pf-5 X940 inoculation was also analyzed in one of the most important crops in the world: Zea mays (maize). Pf-5 X940 was able to increase maize productivity after 30 days of growth in soil conditions (Figure 8). Importantly, this phenotype was also associated with an increase in nitrogen compounds (ammonium and nitrate) in soil (Table 1). In addition, Pf-5 and Pf-5 X940 showed no significant differences of persistence under soil microcosms (Figure 9). These results suggest that inoculation with
Pf-5 X940 could be an effective strategy to increase the productivity of crops in nitrogen-poor soils.

\section{Discussion}

The genus Pseudomonas has gone through many taxonomic modifications over the past 50 years. Thus, many bacteria were moved to other genera, families and orders [46], [76], [77], [78], [79], [80]. Earlier studies considered that there were not any nitrogen-fixing strains within the genus Pseudomonas. In fact, the inability to fix nitrogen by Pseudomonas species had been proposed as an important taxonomic character [46], [47]. However, recent studies have demonstrated that some strains belonging to the genus Pseudomonas sensu stricto, such as Azotobacter vinelandii AvOP, Pseudomonas stutzeri A1501, Pseudomonas stutzeri DSM4166, Pseudomonas azotifigens $6 \mathrm{HT} 33 \mathrm{~b}^{\mathrm{T}}$ and Pseudomonas sp. K1, do have the capability to fix nitrogen [23], [45], [81], [82], [83], [84], [85]. In 

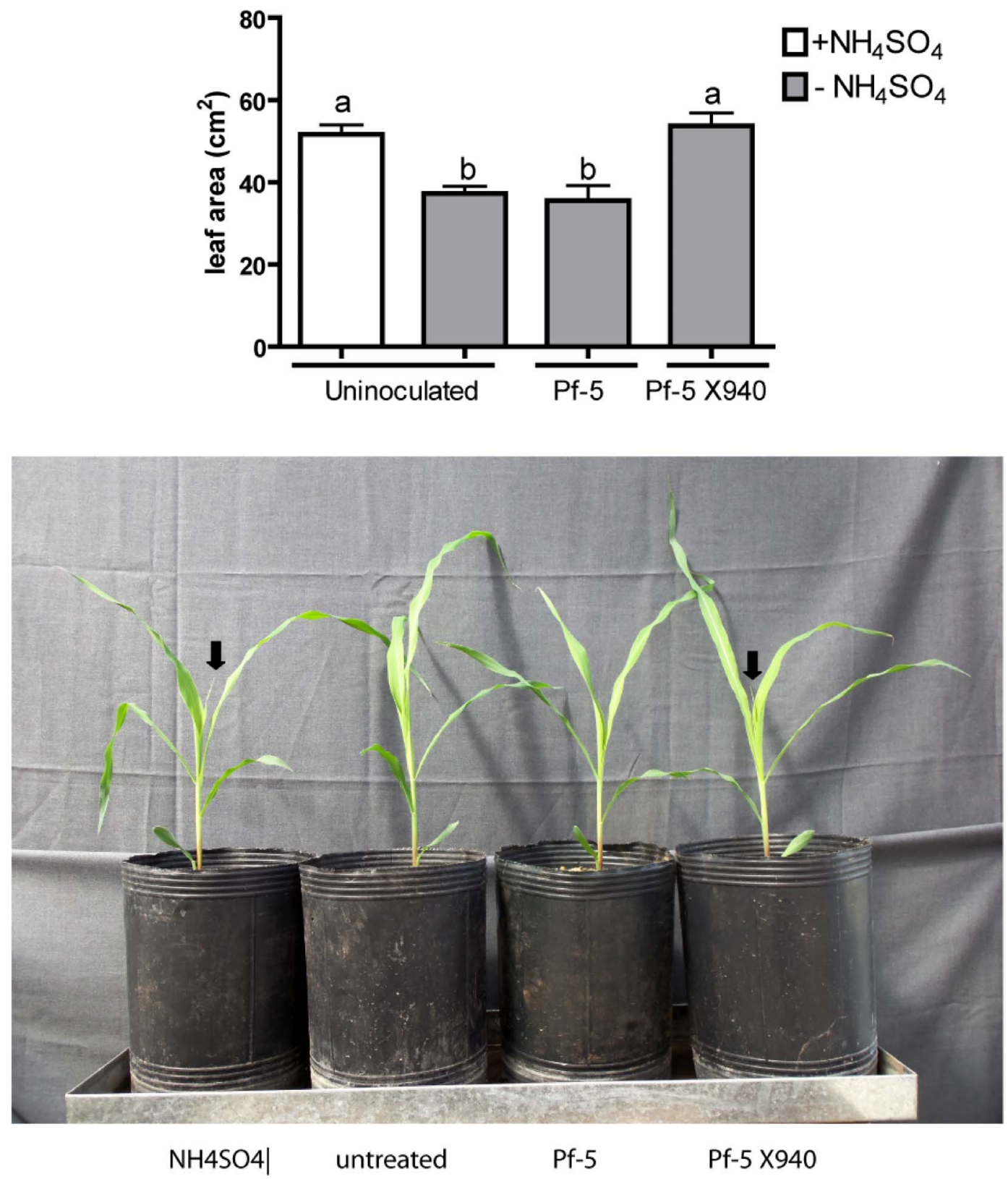

Figure 8. Effect of the inoculation with PF-5 X940 on maize growth. We analyzed the productivity (the area of the third leaf) of plants inoculated with Pf-5 and Pf-5 X940 in the presence $\left(+\mathrm{NH}_{4} \mathrm{SO}_{4}\right)$ or absence $\left(-\mathrm{NH}_{4} \mathrm{SO}_{4}\right)$ of nitrogen in the soil. Arrows indicate the presence of the fourth leaf. The statistical analysis was carried out with ANOVA followed by Tukey's contrast test $(* * * p<0.001)$. doi:10.1371/journal.pone.0063666.g008

addition, the genetic organization of the nif genes in $P$. stutzeri shows a high degree of similarity to that of $A$. vinelandii AvOP [23], and the homology-modeled three-dimensional structure of the $P$. stutzeri nitrogenase, based on the published x-ray crystal structure of $A$. vinelandii nitrogenase, confirmed that the catalytic sites of these nitrogenases are extremely conserved (Figure S5). Furthermore, in both Pseudomonas stutzeri strains, the nif genes have been found within genomic islands [23], [45]. The localization within these mobile elements suggests that these genes were acquired by horizontal transfer via genomic islands.

Despite the advances in genetic engineering previously revealed [32], [33], [34], [35], [36], [37], [38], [39], [40], [41], [46], genetic modification approaches for the development of nitrogen- fixing inoculants derived from strains unable to fix nitrogen have not yet been explored. The main obstacle to meet the controlled and efficient transfer of nif genes between strains may be that the minimum number of essential genes needed for the biosynthesis of a functional nitrogenase are not yet known exactly. Even without considering this constraint, the biosynthesis of nitrogenase requires a large set of genes (at least 16 nif genes) and this vast set of nif genes are usually localized in different regions of the bacterial genome [3], [86], [87]. Thus, the construction of a transferable and easily manipulated vector (such as plasmids and cosmids) containing all nif genes required to produce an active nitrogenase is a genetic engineering challenge. 


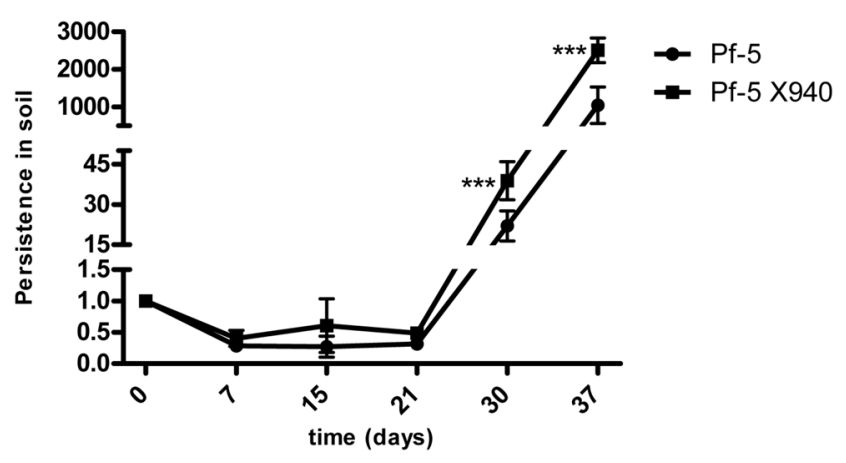

Figure 9. Persistence of bacteria in soil. Sterile soil was inoculated with Pf-5 or Pf-5 X940. Persistence was expressed as a percentage of the number of colony forming units at time zero, that was taken as 1 . The experiment was repeated three independent times. The statistical analysis was carried out with t-test $(* * \mathrm{p}<0.001)$.

doi:10.1371/journal.pone.0063666.g009

In the present work, we used Pseudomonas protegens Pf-5 as the receptor of nitrogen-fixation genes from Pseudomonas stutzeri A1501 (Figure 1, Figure 2). As the complete genome of Pf-5 is available [49], [88], we can state that this strain has no nitrogen-fixation genes. Therefore, the growth in the absence of nitrogen, the expression of nif genes and the nitrogenase activity observed in the recombinant bacterium Pf-5 X940 is strong empirical evidence of the transfer of a functional nitrogenase complex between two Pseudomonas strains (Figure 3, Figure 4). This controlled and efficient transfer system of nif genes will allow for assessment of the minimum number of essential genes required to form a functional nitrogenase complex. This can be achieved through deletions of different regions of the cosmid X940 or through new constructions. This new model of transfer will also allow studying how nitrogen-fixation genes adapt to different hosts, from gene transcription to the final assembly of the nitrogenase complex [89], [90], [91]. In addition, the results described in the present work support the horizontal transfer hypothesis previously suggested by phylogenetic analyses.

In P. stutzeri A1501 and other diazotrophic Proteobacteria, the expression of nif genes is positively controlled by a specific alternative sigma factor named NifA. The nifA gene (PST1313) of $P$. stutzeri A1501 is present within a nitrogen fixation island (PST1306-PST1359). On the other hand, the mechanism for post-transcriptional modification of nitrogenase in P. stutzeri A1501 has not yet been described, but several studies have suggested a nitrogenase "switch off" and "switch on" after ammonium shock and nitrogen deficiency in this strain, respectively [52], [57]. Here, we observed constitutive expression of nif genes and unaltered activity of nitrogenase in the recombinant strain $P$. protegens $\mathrm{Pf}-5$ X940 in the presence or absence of nitrogen in the medium (Figure 4). More specifically, we showed expression of the nifA gene in Pf-5 X940 growing on medium supplemented or not with ammonium (Figure 4). Considering this result, the expression pattern of nif structural (nifH) and biosynthetic (nifB) genes in this recombinant strain is not unexpected (Figure 4). In this context, it could be attractive to explore the role of native alternative sigma factors in the positive control of the expression of nif genes directly and/or via NifA. Here, we also showed that nitrogenase regulation depends on the genome context (Figure 4). Although our study does not describe the mechanisms underlying ammoniumrepressed nitrogenase in $P$. stutzeri A1501, it is possible that the recombinant Pseudomonas strains developed in this study and the
Table 1. Quantification of ammonium and nitrate concentration in maize cultivation soil treated or not (uninoculated) with nitrogen (ammonium), wild-type strain (Pf-5) and recombinant bacterium (Pf-5 X940).

\begin{tabular}{lll}
\hline & & \\
\hline \multirow{2}{*}{ Treatment } & \multicolumn{2}{l}{ Nitrogen compounds in maize cultivation soil $(\mu \mathrm{M})$} \\
\cline { 2 - 3 } & Ammonium & Nitrate \\
\hline Ammonium & $2.77 \pm 0.02$ & $4.77 \pm 0.81$ \\
Uninoculated & $2.45 \pm 0.03$ & $1.44 \pm 0.11$ \\
Pf-5 & $2.59 \pm 0.08$ & $0.57 \pm 0.81$ \\
P-5 X940 & $295 \pm 490$ & $110 \pm 100$ \\
\hline
\end{tabular}

All values are the mean \pm SD of two independent measurements. doi:10.1371/journal.pone.0063666.t001

new strains derived from the latter will help to further explore this issue.

In association with the constitutive nitrogenase activity, $P$. protegens Pf-5, P. putida KT2440, $P$. veronii DSM11331 and $P$. taetrolens IAM1653 but not $P$. balearica SP1402 and $P$. stutzeri CGUG11256 transformed with X940 release large amount of ammonium to the medium (Figure 4), suggesting that the manipulation of nif expression and nitrogenase activity could have an indirect effect on ammonium release. Similarly, it has been recently observed that more ammonium is excreted when a plasmid containing nifA under a constitutive promoter is introduced into the ammonium transporter $\mathrm{AmtB}$ mutant derived from the natural nitrogen-fixing bacterium Pseudomonas stutzeri A1501 [57].

Regarding the field of technology, in this work we showed that it is feasible to increase the ammonium available in the medium and hence the productivity of plants through the inoculation with recombinant bacteria expressing a heterologous nitrogenase (Figure 4, Figure 5, Figure 6, Figure 7, Figure 8, Table 1). We selected Pf-5 as the receptor of nitrogen-fixation genes because this bacterium is currently used as a commercial inoculant for biological control [88], [58]. Therefore, the recombinant strain Pf-5 X940 could increase the productivity of crops through different mechanisms. In addition, the technology of nif transfer used in this work can be applied to other host strains (Figure 4), thus opening the possibility to develop a new family of recombinant inoculants. On the other hand, we found that the inoculation with Pf-5 was effective both for dicots (alfalfa and Arabidopsis) and monocots (fescue and maize) (Figure 5, Figure 6, Figure 7, Figure 8). Therefore, we can speculate that the new family of recombinant inoculants could potentially be used in many commercial crops. In addition, we carried out several experiments that facilitate the release of the genetically modified organism Pf-5 X940: the clone Pf-5 X940 has only one insertion of cosmid X940 (Figure 2) and the genome walking describing the localization of this insertion (Figure S3).

Despite the great potential of this new technology, it is essential not to underestimate its complexities. In the technical area, all experiments were performed under non-agricultural conditions, so it cannot be ruled out that the recombinant strain may be displaced by indigenous microorganisms or not fix nitrogen in some soils with different physico-chemical features. In the regulatory context, the dysregulation of Pf-5 X940 may be too expensive because this strain has more than fifty transgens which can be allergenic and/or toxic to animals or humans. This problem could be reduced if the recombinant bacteria are not found in the aerial plant parts. In addition, before the release of Pf- 
5 X940 an evaluation of the ecological impact of its application on the microbial genetic structure is needed [25], [26], [30].

In conclusion, here we describe a new technology to develop nitrogen-fixing recombinant bacteria and its application to increase plant growth under nitrogen-deficient conditions, opening a new vista in agricultural biotechnology.

\section{Supporting Information}

Figure S1 Schematic representation of X940 cosmid containing nif genes from A1501.

(TIF)

Figure S2 The presence of nifH gene within the recombinant Pseudomonas strains.

(TIF)

Figure S3 Schematic representation of genome walking assay (X940 cosmid).

(TIF)

Figure S4 Effect of PST1307-1312 region in adaptation of nif genes to Pf-5.

(TIF)

Figure S5 Overlapping of $P$. stutzeri A1510 nitrogenase homology-modeled structure (light blue) onto $A$. vinelandii nitrogenase crystallographic structure (pdbID:1M1N) (green). $\mathrm{Fe}(8)-\mathrm{S}(7)$ cluster (left box), $\mathrm{Fe}(7)-\mathrm{Mo}-\mathrm{S}(9)-$ $\mathrm{N}$ cluster (right box), HCA (3- hydroxy-3-carboxy-adipic acid) and cysteines involved in the binding to the clusters are shown. This

\section{References}

1. Shah Z, Shah SH, Peoples MB, Schwenke GD, Herridge DF (2003) Crop residue and fertilizer $\mathrm{N}$ effects on nitrogen fixation and yields of legume-cereal rotations and soil organic fertility. Field Crop Res 83: 1-11.

2. Triplett EW (1996) Diazotrophic endophytes: progress and prospects for nitrogen fixation in monocots. Plant and Soil 186: 29-38.

3. Dos Santos PC, Fang Z, Mason SW, Setubal JC, Dixon R (2012) Distribution of nitrogen fixation and nitrogenase-like sequences amongst microbial genomes. BMC Genomics 13: 162

4. Peters JW, Szilagyi RK (2006) Exploring new frontiers of nitrogenase structure and mechanism. Curr Opin Chem Biol 10: 101-108.

5. Lobo AL, Stephen H (1988) Zinder Diazotrophy and Nitrogenase Activity in the Archaebacterium Methanosarcina barkeri. Appl Environ Microbiol 54: 1656-1661.

6. Wolk CP, Ernst A, Elhai J (1994) Heterocyst metabolism and development. In The Molecular Biology of Cyanobacteria. Bryant, D.A. (ed.). Dordrecht, the Netherlands: Kluwer Academic Publishers, 769-823.

7. Newton WE (2007) Physiology, biochemistry and molecular biology of nitrogen fixation. In Biology of The Nitrogen Cycle. Edited by H. Bothe, S. J. Ferguson \& W. E. Newton. Amsterdam: Elsevier. 109-129.

8. Rai AN, Bergman B, Rasmussen U (2002) Cyanobacteria in symbiosis. Kluwer Academic, Dordrecht, Netherlands.

9. Jones KM, Kobayashi H, Davies BW, Taga ME, Walker GC (2007) How rhizobial symbionts invade plants: the Sinorhizobium-Medicago model. Nat Rev Microbiol 5: 619-633.

10. Gehringer MM, Pengelly JJ, Guddy WS, Fieker C, Forster PI, et al. (2010) Host selection of symbiotic cyanobacteria in 31 species of the Australian cycad genus: Macrozamia (Zamiaceae). Mol Plant Microbe Interact 23: 811-822.

11. Gyaneshwar P, Hirsch AM, Moulin L, Chen WM, Elliott GN, et al. (2011). Legume-nodulating betaproteobacteria: diversity, host range, and future prospects. Mol Plant Microbe Interact 24: 1276-1288.

12. Op den Camp RH, Polone E, Fedorova E, Roelofsen W, Squartini A, et al. (2012) Nonlegume Parasponia andersonii deploys a broad rhizobium host range strategy resulting in largely variable symbiotic effectiveness. Mol Plant Microbe Interact 25: 954-963.

13. Pawlowski K, Demchenko KN (2012) The diversity of actinorhizal symbiosis. Protoplasma 249: 967-979.

14. James EK (2000) Nitrogen fixation endophytic and associative symbiosis. Field Crops Research 65: 197-209.

15. Ladha JK, Reddy PM (1995) Extension of nitrogen fixation to rice necessity and possibilities. Geojournal 35: 363-372.

16. Wood CC, Islam N, Ritchie RJ, Kennedy IR (2001) A simplified model for assessing critical parameters during associative N-15(2) fixation between Azospirillum and wheat. Australian Journal of Plant Physiology 28: 969-974. image was rendered with PyMOL (Python Molecular Graphics 1.3, 2009-2010, DeLano Scientific LLC, San Carlos, CA) also used to calculate the bond length between the clusters and cysteines sulfur (measured mean length for $A$. vinelandii $=2.3 \AA$ and predicted mean length for $P$. stutzeri $=2.25 \pm 0.06 \AA$ ).

(TIF)

Table S1 Primers used in this work. (DOC)

Table S2 The statistical analysis of bacterial growth. (XLSX)

\section{Dataset S1 Nucleotide sequence of cosmid X940.} (TXT)

\section{Acknowledgments}

We thank Lorena La Fuente, Ema Soto, Carmen Soria, Carolina Castagnet and Graciela Fox for their technical support. We thank Dr. Adolfo Daniel Fox (http://www.foxlab.com.ar/) for his help in the quantification of nitrogen compounds in soil.

\section{Author Contributions}

Conceived and designed the experiments: NDA GS. Performed the experiments: LS GS MM ARF CL MC MA EP ADP NDA. Analyzed the data: LS GS MM ARF CL MC MA EP ADP NDA. Contributed reagents/ materials/analysis tools: LS GS MM ARF CL MC MA EP ADP NDA. Wrote the paper: NDA GS.

17. Boddey RM, Döbereiner J (1988) Nitrogen fixation associated with grasses and cereals: Recent results and perspectives for future research. Plant and Soil 108: 53-65.

18. Boddey RM, Urquiaga S, Reis V, Döbereiner J (1991) Biological nitrogen fixation associated with sugar cane. Plant and Soil 137: 111-117.

19. Dorbereiner J, Reis VM, Paula MA, Olivares F (1993) Endophytic diazotrophs in sugar cane, cereals and tuber plants. In New Horizons in Nitrogen Fixation. Eds. R Palacios, J Mora and W E Newton. 671-676. Kluwer Academic Publishers, Dordrecht, The Netherlands.

20. Boddey RM (1995) Biological nitrogen fixation in sugar cane: a key to energetically viable biofuel production. Crit Rev Plant Sci 14: 263-279.

21. Palus JA, Borneman J, Ludden PW, Triplett EW (1996) A diazotrophic bacterial endophytes isolated from stems of Zea mays L. and Zea luxurians Iltis and Doebley. Plant and Soil 186: 135-142.

22. Reis VM, Döbereiner J (1998) Effect of high sugar concentration on nitrogenase activity of Acetobacter diazotrophicus. Arch Microbiol 171: 13-18.

23. Yan Y, Yang J, Dou Y, Chen M, Ping S, et al. (2008) Nitrogen fixation island and rhizosphere competence traits in the genome of root-associated Pseudomonas stutzeri A1501. PNAS 105: 7564-7569.

24. Dobbelaere S, Croonenborghs A, Thys A, Vande Broek A, Vanderleyden J (1999) Analysis and relevance of the phytostimulatory effect of genetically modified Azospirillum brasilense strains upon wheat inoculation. Plant Soil 212: $155-164$.

25. Girlanda M, Perotto S, Moenne-Loccoz Y, Bergero R, Lazzari A, et al. (2001) Impact of biocontrol Pseudomonas fluorescens CHA0 and a genetically modified derivative on the diversity of culturable fungi in the cucumber rhizosphere. Appl Environ Microbiol 67: 1851-1864.

26. Shaukat SS, Siddiqui IA (2003) Impact of biocontrol agents Pseudomonas fluorescens $\mathrm{CHA} 0$ and its genetically modified derivatives on the diversity of culturable fungi in the rhizosphere of mungbean. J Appl Microbiol 95: 1039-1048.

27. Spaepen S, Verses W, Gocke D, Pohl M, Steyaert J, et al. (2007) Characterization of phenylpyruvate decarboxylase, involved in auxin production of Azospirillum brasilense. J Bacteriol 189: 7626-7633.

28. Beyeler M, Keel C, Michaux P, Haas D (1999) Enhanced production of indole3 -acetic acid by a genetically modified strain of Pseudomonas fluorescens CHAO affects root growth of cucumber, but does not improve protection of the plant against Pythium root rot. FEMS Microbiol Ecol 28: 225-233.

29. Spaepen S, Dobbelaere S, Croonenborghs A, Vanderleyden J (2008) Effects of Azospirillum brasilense indole-3-acetic acid production on inoculated wheat plants. Plant Soil 312: 15-23.

30. Baudoin E, Lerner A, Mirza MS, El Zemrany H, Prigent-Combaret C, et al. (2010) Effects of Azospirillum brasilense with genetically modified auxin biosynthesis 
gene ipdC upon the diversity of the indigenous microbiota of the wheat rhizosphere. Res Microbiol 161: 219-226.

31. Zhang X, Huang Y, Harvey PR, Ren Y, Zhang G, et al. (2011) Enhancing plant disease suppression by Burkholderia vietnamiensis through chromosomal integration of Bacillus subtilis chitinase gene chil13. Biotechnol Lett 34: 287-293.

32. Dixon RA, Postgate JR (1971) Transfer of nitrogen-fixation genes by conjugation in Klebsiella pneumoniae. Nature 234: 47-48.

33. Streicher S, Gurney E, Valentine RC (1971) Transduction of the nitrogenfixation genes in Klebsiella pneumoniae. PNAS 68: 1174-1177.

34. Dixon RA, Postgate JR (1972) Genetic transfer of nitrogen fixation from Klebsiella pneumoniae to Escherichia coli. Nature 237: 102-103.

35. Postgate JR, Kent HM (1987) Qualitative Evidence for Expression of Klebsiella pneumoniae nif in Pseudomonas putida. Journal of General Microbiology 133: 25632566 .

36. Martínez E, Palacios R, Sanchez F (1987) Nitrogen fixing nodules induced by Agrobacterium tumefaciens harboring Rhizobium phaseoli plasmids. J Bacteriol 169: 2828-2834.

37. Sullivan JT, Patrick HN, Lowther WL, Scott DB, Ronson CW (1995) Nodulating strains of Rhizobium loti arise through chromosomal symbiotic gene transfer in the environment. PNAS 92: 8985-8989.

38. Sullivan JT, Eardly BD, Van Berkum P, Ronson CW (1996) Four unnamed species of nonsymbiotic rhizobia isolated from the rhizosphere of Lotus corniculatus. Appl Environ Microbiol 62: 2818-2825.

39. Sullivan JT, Ronson CW (1998) Evolution of rhizobia by acquisition of a 500-kb symbiosis island that integrates into a phe-tRNA gene. PNAS 28: 5145-5149.

40. Tan Z, Hurek T, Vinuesa P, Mûller P, Ladha JK, et al. (2001) Specific detection of Bradyrhizobium and Rhizobium strains colonizing rice (Oryza sativa) roots by $16 \mathrm{~S}-$ 23S ribosomal DNA intergenic spacer-targeted PCR. Appl Environ Microbiol 67: 3655-3664.

41. Cummings SP, Gyaneshwar P, Vinuesa P, Farruggia FT, Andrews M, et al. (2009) Nodulation of Sesbania species by Rhizobium (Agrobacterium) strain IRBG74 and other rhizobia. Environ Microbiol 11: 2510-2525.

42. Raymond J, Siefert JL, Staples CR, Blankenship RE (2004) The natural history of nitrogen fixation. Mol. Biol. Evol. 21, 541-554.

43. Kechris K, Lin JC, Bickel PJ, Glazer AN (2006) Quantitative exploration of the occurrence of lateral gene transfer by using nitrogen fixation genes as a case study. PNAS 103: 9584-9589.

44. Latysheva N, Junker VL, Palmer WJ, Codd GA, Barker D (2012) The evolution of nitrogen fixation in cyanobacteria. Bioinformatics 28, 603-606.

45. Yu H, Yuan M, Lu W, Yang J, Dai S, et al. (2011). Complete genome sequence of the nitrogen-fixing and rhizosphere-associated bacterium Pseudomonas stutzeri strain DSM4166. J Bacteriol 193: 3422-3423.

46. Anzai Y, Kim H, Park JY, Wakabayashi H, Oyaizu H (2000) Phylogenetic affiliation of the pseudomonads based on $16 \mathrm{~S}$ rRNA sequence. Int J Syst Evol Microbiol 4: 1563-1589.

47. Young JPW (1992) Phylogenetic classification of nitrogen fixing organisms. In Biological Nitrogen Fixation, 43-86. Edited by G. Stacey, R. H. Burris \& H. J. Evans. New York:Chapman \& Hall. 1544.

48. Yan Y, Ping S, Peng J, Han Y, Li L, et al. (2010) Global transcriptional analysis of nitrogen fixation and ammonium repression in root-associated Pseudomonas stutzeri A1501. BMC Genomics 11: 11.

49. Paulsen IT, Press CM, Ravel J, Kobayashi DY, Myers GS, et al. 2005. Complete genome sequence of the plant commensal Pseudomonas fluorescens Pf-5. Nat Biotechnol 23: 873-878.

50. Howell CR, Stipanovic RD (1979) Control of Rhizoctonia solani on cotton seedlings with Pseudomonas fluorescens with an antibiotic produced by the bacterium. Phytopathology 69: 480-482.

51. Ramette A, Frapolli M, Fischer-Le Saux M, Gruffaz C, Meyer JM, et al. (2011) Pseudomonas protegens sp. nov., widespread plant-protecting bacteria producing the biocontrol compounds 2,4-diacetylphloroglucinol and pyoluteorin. Syst Appl Microbiol 34: 180-188.

52. Desnoues N, Lin M, Guo X, Ma L, Carreño-Lopez R, et al. (2003) Nitrogen fixation genetics and regulation in a Pseudomonas stutzeri strain associated with rice. Microbiology 149: 2251-2262.

53. Nelson KE, Weinel C, Paulsen IT, Dodson RJ, Hilbert H, et al. (2002) Complete genome sequence and comparative analysis of the metabolically versatile Pseudomonas putida KT2440. Environ Microbiol 4: 799-808.

54. Elomari M, Coroler L, Hoste B, Gillis M, Izard D, et al. (1996) DNA relatedness among Pseudomonas strains isolated from natural mineral waters and proposal of Pseudomonas veronii sp. nov. Int J Syst Bacteriol 46: 1138-1144.

55. Anzai Y, Kudo Y, Oyaizu H (1997) The phylogeny of the genera Chryseomonas, Flavimonas, and Pseudomonas supports synonymy of these three genera. Int J Syst Bacteriol 47: 249-251.

56. Bennasar A, Rosselló-Mora R, Lalucat J, Moore ER (1996) 16S rRNA gene sequence analysis relative to genomovars of Pseudomonas stutzeri and proposal of Pseudomonas balearica sp. nov. Int J Syst Bacteriol 46: 200-205.

57. Zhang T, Yan Y, He S, Ping S, Alam KM, et al. (2012) Involvement of the ammonium transporter $\mathrm{AmtB}$ in nitrogenase regulation and ammonium excretion in Pseudomonas stutzeri A1501. Res Microbiol 163: 332-339.

58. Mavrodi DV, Loper JE, Paulsen IT, Thomashow LS (2009) Mobile genetic elements in the genome of the beneficial rhizobacterium Pseudomonas fluorescens Pf-5. BMC Microbiol 9: 8.
59. Ayub ND, Tribelli PM, López NI (2009) Polyhydroxyalkanoates are essential for maintenance of redox state in the Antarctic bacterium Pseudomonas sp. 14-3 during low temperature adaptation. Extremophiles 13: 59-66.

60. Satoshi Y, Harayama S (1995) PCR Amplification and Direct Sequencing of gyrB Genes with Universal Primers and Their application to the Detection and Taxonomic Analysis of Pseudomona putida Strains. Appl Environ Microbiol 61: 1104-1109.

61. Zhang Y, Pohlmann EL, Ludden PW, Roberts GP (2000) Mutagenesis and functional characterization of the $g \ln B$, glnA, and nifA genes from the photosynthetic bacterium Rhodospirillum rubrum. J Bacteriol 182: 983-992.

62. Baker G, Smith JJ, Cowan DA (2003) Review and re-analysis of Domain-specific $16 \mathrm{~S}$ primers. J Microbiol Methods 55: 541-555.

63. Chaney AL, Marbach EP (1962) Modified reagents for determination of urea and ammonia. Clin Chem 8: 130-132.

64. Galimand M, Perroud B, Delorme F, Paquelin A, Vieille C, et al. (1989) Identification of DNA regions homologous to nitrogen fixation genes nifE, nifUS and fixABC in Azospirillum brasilense Sp7. J Gen Microbiol 135: 1047-1059.

65. Bradford MM (1976) A rapid and sensitive method for the quantitation of microgram quantities of protein utilizing the principle of protein-dye binding. Anal Biochem 72: 248-254.

66. Wheatley RE, MacDonald R, Smith A (1989) Extraction of nitrogen from soils. Biol Fert Soils 8: 189-190.

67. Krom MD (1980). Spectrophotometric determination of ammonia: a study of a modified Berthelot reaction using salicylate and dichloroisocyanurate. Analyst 105: 305-316.

68. Angle JS, Levin MA, Gagliardi JV, McIntosh MS (1995) Validation of Microcosms for Examining the Survival of Pseudomonas aureofaciens (lacZY) in Soil. Appl Environ Microbiol 61: 2835-2839.

69. Soto G, Alleva K, Mazzella MA, Amodeo G, Muschietti JP (2008) AtTIP1;3 and AtTIP5;1, the only highly expressed Arabidopsis pollen-specific aquaporins, transport water and urea. FEBS Lett 582: 4077-4082.

70. Soto G, Fox R, Ayub N, Alleva K, Guaimas F, et al. (2010) TIP5;1 is an aquaporin specifically targeted to pollen mitochondria and is probably involved in nitrogen remobilization in Arabidopsis thaliana. Plant J 64: 1038-1047.

71. Markel E, Maciak C, Butcher BG, Myers CR, Stodghill P, et al. (2011) An extracytoplasmic function sigma factor-mediated cell surface signaling system in Pseudomonas syringae pv. tomato DC3000 regulates gene expression in response to heterologous siderophores. J Bacteriol 193: 5775-5783.

72. Soto G, Stritzler M, Lisi C, Alleva K, Pagano ME, et al. (2011) Acetoacetyl-CoA thiolase regulates the mevalonate pathway during abiotic stress adaptation. J Exp Bot 62: 5699-5711.

73. Schwede T, KoppJ, Guex N, Peitsch MC (2003) SWISS-MODEL: An automated protein homology-modeling server. Nucleic Acids Res 31: 3381-3385.

74. Mozzicafreddo M, Cuccioloni M, Cecarini V, Eleuteri AM, Angeletti M (2009) Homology modeling and docking analysis of the interaction between polyphenols and mammalian 20S proteasomes. J Chem Inf Model 49: 401-409.

75. Einsle O, Tezcan FA, Andrade SL, Schmid B, Yoshida M, et al, (2002) Nitrogenase MoFe-protein at 1.16 A resolution: a central ligand in the FeMocofactor. Science 297: 1696-700.

76. Palleroni NJ (2003) Prokaryote taxonomy of the 20th century and the impact of studies on the genus Pseudomonas: a personal view. Microbiology 149: 1-7.

77. Stanier RY, Palleroni NJ, Doudoroff M (1966) The aerobic pseudomonads: a taxonomic study. J Gen Microbiol 43: 159-271.

78. Kersters K, Ludwig W, Vancanneyt M, Devos P, Gillis M, et al. (1996) Recent changes in the classification of the pseudomonads: an overview. Syst Appl Microbiol 19: 465-477.

79. Palleroni NJ (2008) The road to the taxonomy of Pseudomonas. In: Cornelis P, editor. Pseudomonas. Genomics and molecular biology. Norfolk: Caister Academic 1-18.

80. Özen AI, Ussery DW (2012) Defining the Pseudomonas genus: where do we draw the line with Azotobacter? Microb Ecol 63: 239-248.

81. Rediers H, Vanderleyden J, De Mot R (2004) Azotobacter vinelandii: a Pseudomonas in disguise?. Microbiology 150: 1117-1119.

82. Young JM, Park DC (2007) Probable synonymy of the nitrogen-fixing genus Azotobacter and the genus Pseudomonas. Int J Syst Evol Microbiol 57: 2894-2901.

83. Özen AI, Ussery DW (2012) Defining the Pseudomonas genus: where do we draw the line with Azotobacter? Microb Ecol 63: 239-248.

84. Hatayama K, Kawai S, Shoun H, Ueda Y, Nakamura A (2005) Pseudomonas azotifigens sp. nov., a novel nitrogen-fixing bacterium isolated from a compost pile. Int J Syst Evol Microbiol 55: 1539-1544.

85. Mirza MS, Mehnaz S, Normand P, Prigent-Combaret C, Moënne-Loccoz Y, et al. (2006) Biology and Fertility of Soils 43: 163-170.

86. Dean DR, Jacobson MR (1992) Biochemical Genetics of Nitrogenase. In Biological Nitrogen Fixation. Chapman and Hall, New York. 763-834.

87. Merrick MJ (1993) Organisation and regulation of nitrogen fixation genes. In New Horizons in Nitrogen Fixation, Proceedings of the 9th International Congress on Nitrogen Fixation. Kluwer Academic, Dordrecht. 43-54.

88. Loper JE, Kobayashi DY, Paulsen IT (2007) The Genomic Sequence of Pseudomonas fluorescens Pf-5: Insights Into Biological Control. Phytopathology 97: 233-238.

89. Dixon R, Kahn D (2004) Genetic regulation of biological nitrogen fixation. Nat Rev Microbiol 2: 621-631.

90. Martinez-Argudo I, Little R, Shearer N, Johnson P, Dixon R (2005) Nitrogen fixation: key genetic regulatory mechanisms. Biochem Soc Trans 33: 152-156.

91. Hamilton TL, Ludwig M, Dixon R, Boyd ES, Dos Santos PG, et al. (2011) Transcriptional profiling of nitrogen fixation in Azotobacter vinelandii. J Bacteriol 193: $4477-4486$ 